\title{
Synthesis, Polymer Reactions, and Characterization of Polystyrene-Polyoxetane Composite Resins Having a Pendant Terminal Bromide of 1-Oxapolymethylene Spacers Bound to the Styryl Group at the Para Position
}

\author{
Masatoshi Motor, Eiichi Saito, Satoshi Kyoda, Nobuyuki TaKahata, \\ Seiji NagaI, and Akio Arano \\ Department of Chemistry and Engineering Chemistry, \\ Faculty of Technology, Kanazawa University, \\ Kodatsuno, Kanazawa 920, Japan
}

(Received December 25, 1990)

\begin{abstract}
Polystyrene-polyoxetane composite resins were prepared via two-stage polymerizations using $p$-substituted styrenes $\mathrm{CH}_{2}=\mathrm{CHC}_{6} \mathrm{H}_{4}-\mathrm{O}\left(\mathrm{CH}_{2}\right)_{n} \mathrm{Br}(7 \mathrm{a}$ or $7 \mathbf{b})$, where $n=4$ or 6 , and an isomeric mixture of $m$ - and $p$-[3-(3-methyl-3-oxetanyl)-2-oxapropyl]styrenes (5) as a cross-linking agent. The terminal bromide linked to a styryl ring at the para position through an 1-oxapentamethylene spacer of $7 \mathbf{a}(n=4)$ was applicable to a starting substrate on polymer reactions with some nucleophiles, such as phenols, potassium acetate, and tributylamine, for obtaining polymeric derivatives via several reaction steps. These resins with a pendant quaternary ammonium bromide moiety were also used as phase-transfer catalysts. On the basis of their catalytic activities, qualities and spacer effects of these supporting resins were compared with those of resins obtained by using chloromethylstyrenes instead of $\mathbf{7 a}$ or divinylbenzenes instead of $\mathbf{5}$.
\end{abstract}

KEY WORDS Polystyrene-Polyoxetane Composite Resins / Two-Stage Polymerization / Functional Polymers / Polymer Reactions / Styrene Derivatives /

So far, several cross-linked polymers have been prepared for immobilizing functional groups, which can operate effectively under applied reaction conditions, to these polymers. Among them, chloromethylated divinylbenzen (DVB)-cross-linked polystyrenes have been widely used to synthesize a variety of functional polymers, since several types of these DVBcross-linked polystyrene gels are readily available as commercial reagents and their benzylic chlorides have fairly high reactivities in chemical reactions. However, the choice of using DVB-cross-linked polystyrenes as polymeric supports is not necessarily suitable for designing polymers with high functionalities, owing to hardness, low polarity, hydrophobicity, low swellability, and brittleness. ${ }^{1,2}$
In order to overcome another drawback due to the short spacer arm of chloromethylated polystyrene gels, styrene derivatives $7 \mathbf{b}$ and 8 with a bromine atom at the ends of appropriately long spacers were synthesized and copolymerized with DVB to obtain spacer-modified polystyrene gels which were used as the polymeric support of a phasetransfer catalyst (PTC). ${ }^{3,4}$

Recently it was found that polyoxetane networks were promising polymeric supports which were obtained by cationic ring-opening copolymerization of 3 with bisoxetane $4 .^{5-7}$ An isomeric mixture of $m$ - and $p$-[3-(3-methyl3-oxetanyl)-2-oxapropyl]styrenes (5) is also considered to be a key compound for designing a variety of functionalized polystyrene-poly- 


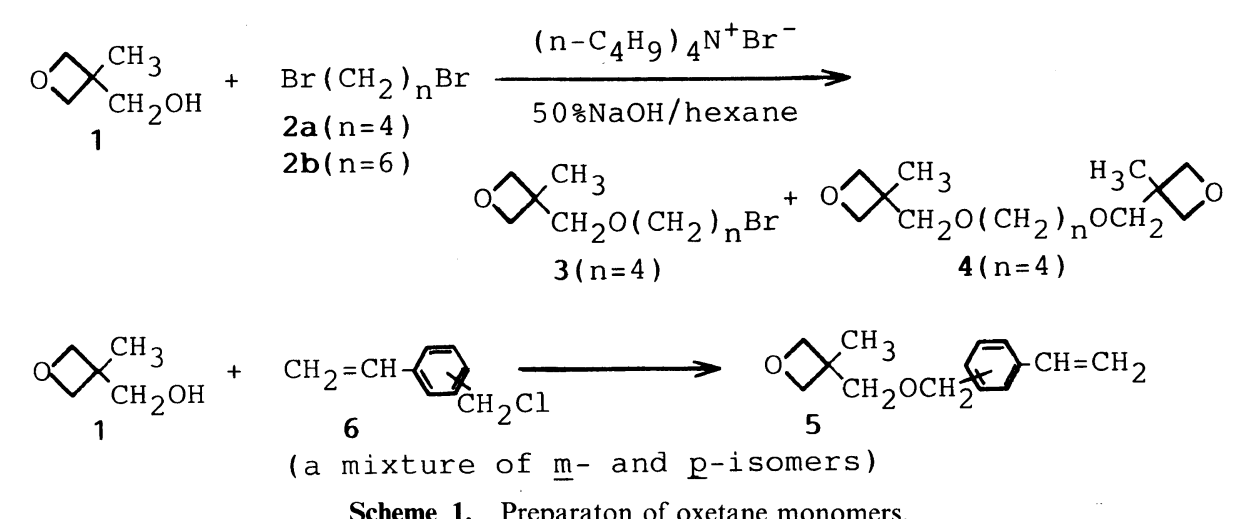

Scheme 1. Preparaton of oxetane monomers.
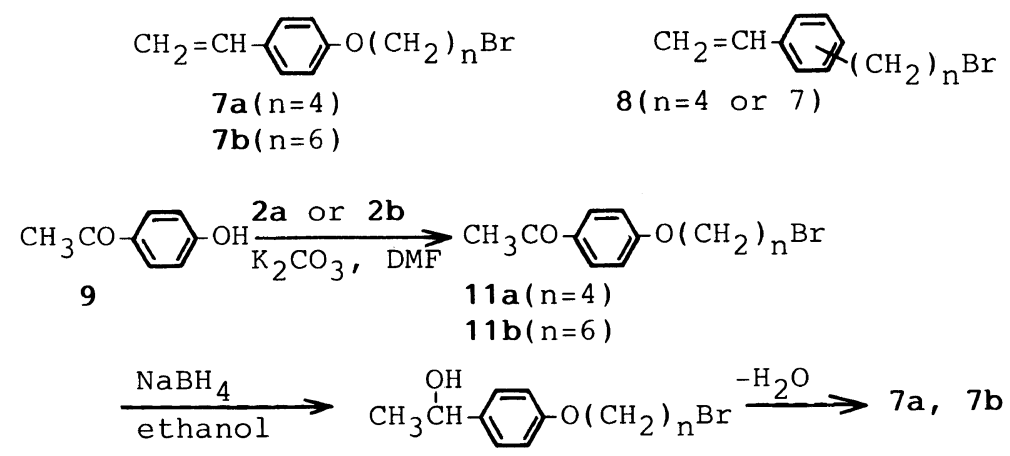

Scheme 2. Preparation of styrene derivatives.

oxetane composite resins via two-stage polymerizations using cataionically ring-opening or radically polymerizable comonomers at each stage. ${ }^{6,8}$ In these ways, several polyoxetane resins and polyoxetane-polystyrene composite resins were prepared having a spacer-separated alkyl bromide at the side chain-end of the polyoxetane main chain, and the characters of these resins were also investigated by using them as supports of polymeric PTCs. ${ }^{7,8}$

This paper describes a new type of polystyrene resins as one of polymeric supports used for designing functional polymers: (1) preparation of polystyrene-polyoxetane composite resins, which have a spacer-separated alkyl bromide at the side chain-end of the polystyrene main chain, by two-stage polymerizations of Methods A and B (Scheme 3), (2) used of these pendant bromides as an original starting substrate for derivatization via several polymer reaction steps, and (3) evaluation of qualities of supporting resins and effects of spacers on the basis of phase-transfer catalytic activities of pendant quaternary ammonium halides anchored to these resins.

\section{EXPERIMENTAL}

\section{Materials}

3-Hydroxymethyl-3-methyloxetane (1) ${ }^{9}$ and oxetane $(12)^{10}$ were prepared according to the literature. 3-(6-Bromo-2-oxahexyl)-3-methyloxetane (3), 1.8-bis(3-methyl-3-oxetanyl)2,7-dioxaoctane (4), and an isomeric mixture of $m$ - and $p$-[3-(3-methyl-3-oxetanyl)-2-oxapropyl]styrenes (5) were prepared under phasetransfer catalytic conditions, following the method reported by us previously. ${ }^{5,8}$

p-(5-Bromo-1-oxapentyl)styrene (7a). 1-(pAcetylphenoxy)-4-bromobutane (11a) ${ }^{7}(10.0 \mathrm{~g}$, 


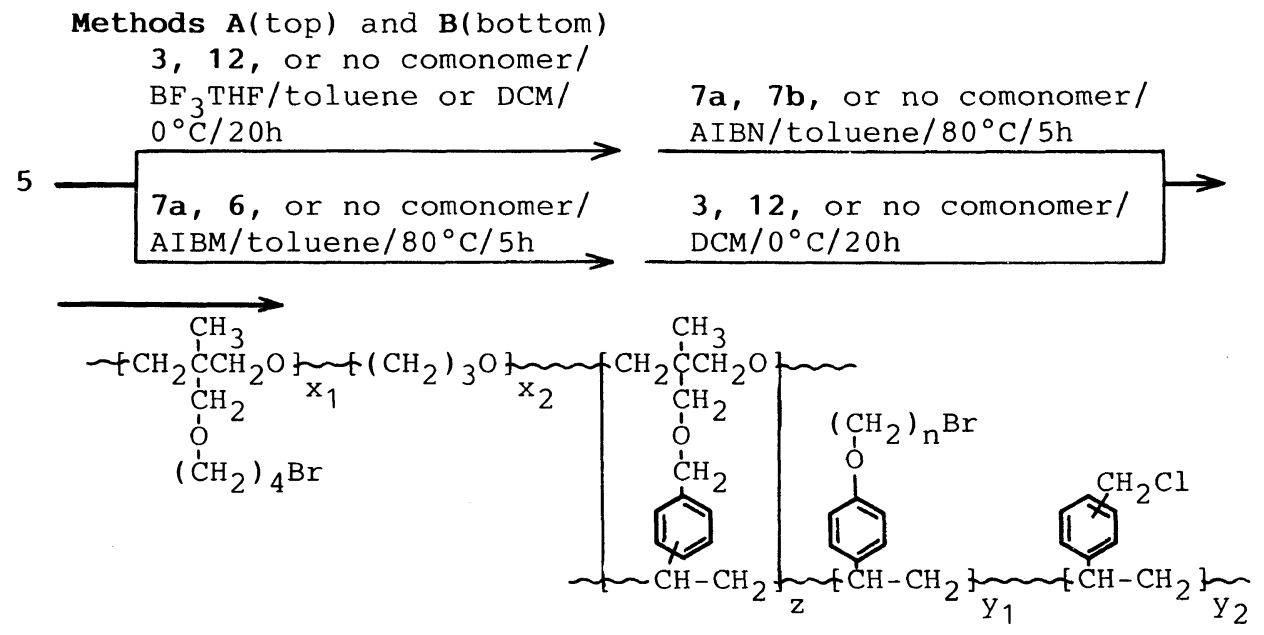

IA, IB: $\mathrm{x}_{1}=\mathrm{x}_{2}=\mathrm{y}_{2}=0, \mathrm{n}=4$; IIA-1, IIA-2: $\mathrm{x}_{1}=\mathrm{y}_{2}=0, \mathrm{n}=4$; IVA: $\mathrm{x}_{1}=\mathrm{x}_{2}=\mathrm{y}_{2}=0, \mathrm{n}=6 ;$ VB: $\mathrm{x}_{1}=\mathrm{x}_{2}=\mathrm{y}_{1}=0 ;$ VIA, VIB: $\mathrm{x}_{1}=\mathrm{y}_{1}=0$;

VIIA, VIIB: $\mathrm{x}_{2}=\mathrm{y}_{1}=\mathrm{y}_{2}=0$

Method C

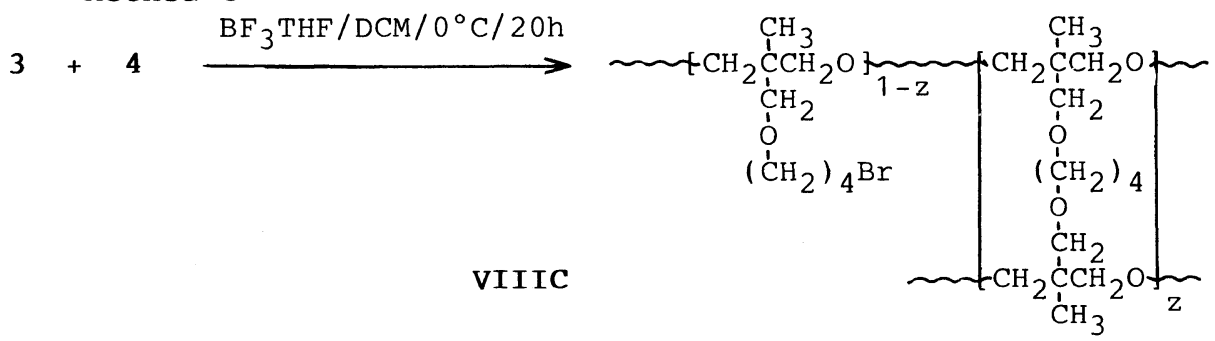

Method D

DVB or no comonomer/

AIBN $/ 80^{\circ} \mathrm{C} / 5 \mathrm{~h}$

$7 a$ or

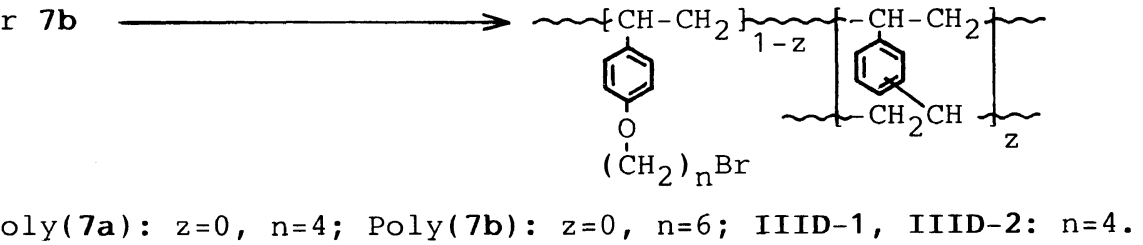

Scheme 3. Preparation of resins by Methods A, B, C, and D.

$36.9 \mathrm{mmol})$ was reduced with $\mathrm{NaBH}_{4}(0.70 \mathrm{~g}$, quinone $(0.1 \mathrm{~g})$, the ether layer was con$15.8 \mathrm{mmol})$ in ethanol $\left(50 \mathrm{~cm}^{3}\right)$ at $50^{\circ} \mathrm{C}$ for $3 \mathrm{~h}$. After adding acetic acid $\left(1.0 \mathrm{~cm}^{3}\right)$ to the resultant solution, the ethanol was evaporated and the residue shaken with water $\left(100 \mathrm{~cm}^{3}\right)$ and ether $\left(100 \mathrm{~cm}^{3}\right)$. The ether layer was separated from the aqueous layer and dried over anhydrous $\mathrm{Na}_{2} \mathrm{SO}_{4}$. After adding hydrocentrated by means of an evaporator and the viscous residue was distilled at $90-110^{\circ} \mathrm{C}$ of bath temperature at $6-8 \mathrm{~Pa}$. The distillate dissolved in ether again was washed with $10 \%$ $\mathrm{NaOH}\left(2 \times 100 \mathrm{~cm}^{3}\right)$ and water successively, and dried over $\mathrm{Na}_{2} \mathrm{SO}_{4}$. The ether solution was evaporated and the residue distilled, after 
adding anhydrous $\mathrm{Cu}(\mathrm{I}) \mathrm{Cl}(30 \mathrm{mg})$ to it, to collect a fraction boilding at $100-105^{\circ} \mathrm{C}$ (9.3 Pa): yield, $68 \%$ based on 11a; IR (neat) $1610,1575,1515$, and 840 (1,4-disubstituted benzene), $1630,990,905$ (vinyl), and $1250 \mathrm{~cm}^{-1}$ (aromatic ether); ${ }^{1} \mathrm{H}$ NMR $\left(\mathrm{CDCl}_{3}\right) \delta=1.2$ $2.2\left[4 \mathrm{H}, \mathrm{m},-\mathrm{CH}_{2}\left(\mathrm{CH}_{2}\right)_{2} \mathrm{CH}_{2}-\right], 3.47(2 \mathrm{H}$, $\left.\mathrm{t}, J=6.4 \mathrm{~Hz}, \mathrm{CH}_{2} \mathrm{Br}\right), 3.98(2 \mathrm{H}, \mathrm{t}, J=5.9 \mathrm{~Hz}$, $\mathrm{OCH}_{2}$ ), 5.11, 5.59, and 6.65 (each $1 \mathrm{H}$, each dd, $J_{\mathrm{ab}}=1.0, J_{\mathrm{ac}}=10.8, J_{\mathrm{bc}}=17.7 \mathrm{~Hz}$, vinyl protons), and $6.25-7.45 \mathrm{ppm}(4 \mathrm{H}, \mathrm{AB}$ quartetlike, ArH).

1-(p-Acetylphenoxy)-6-bromohexane (11b). Obtained in a 74\% yield from $p$-hydroxyacetophenone (9) and 1,6-dibromohexane (2b) in the same way as described for the preparation of 11a: bp $135-148^{\circ} \mathrm{C}(5.3 \mathrm{~Pa})$; IR (neat) 1600, 1575, 1515, and $835(1,4-$ disubstituted benzene), $1680 \quad(\mathrm{C}=\mathrm{O})$, and $1255 \mathrm{~cm}^{-1 \cdot}$ (aromatic ether); ${ }^{1} \mathrm{H} \mathrm{NMR}\left(\mathrm{CDCl}_{3}\right)$ $\delta=1.4-2.1\left[8 \mathrm{H}, \mathrm{m},-\mathrm{CH}_{2}\left(\mathrm{CH}_{2}\right)_{4} \mathrm{CH}_{2}-\right], 2.55$ $\left(3 \mathrm{H}, \mathrm{s}, \mathrm{COCH}_{3}\right), 3.43(2 \mathrm{H}, \mathrm{t}, J=6.6 \mathrm{~Hz}$, $\left.\mathrm{CH}_{2} \mathrm{Br}\right), 4.02\left(2 \mathrm{H}, \mathrm{t}, J=6.2 \mathrm{~Hz}, \mathrm{OCH}_{2}\right)$, 6.8-8.1 ppm (4H, AB quartet-like $\mathrm{ArH})$.

Anal. Calcd for $\mathrm{C}_{14} \mathrm{H}_{19} \mathrm{BrO}_{2}: \mathrm{C}, 56.19 \% ; \mathrm{H}$, $6.41 \%, \mathrm{Br}, 26.70 \%$. Found: $\mathrm{C}, 56.23 \% ; \mathrm{H}$, $6.55 \% ; \mathrm{Br}, 26.95 \%$.

p-(7-Bromo-1-oxaheptyl)styrene (7b). Obtained in a $71 \%$ yield based on the ketone 11b in the same way as that for the preparation of 7a: bp $114-135^{\circ} \mathrm{C}(4.3-4.9 \mathrm{~Pa})$; IR (neat) $1619,1575,1515$, and 840 (1,4-disubstituted benzene), 1639, 990, and 905 (vinyl), and $1259 \mathrm{~cm}^{-1}$ (aromatic ether); ${ }^{1} \mathrm{H} \mathrm{NMR}\left(\mathrm{CDCl}_{3}\right)$ $\delta=1.2-2.0\left[8 \mathrm{H}, \mathrm{m}, \mathrm{CH}_{2}\left(\mathrm{CH}_{2}\right)_{4} \mathrm{CH}_{2}\right], 3.39$ $\left(2 \mathrm{H}, \quad \mathrm{t}, \quad J=6.6 \mathrm{~Hz}, \mathrm{CH}_{2} \mathrm{Br}\right), 3.39(2 \mathrm{H}, \quad i$, $J=6.4 \mathrm{~Hz}, \mathrm{OCH}_{2}$ ), 5.10, 5.58, and 6.64 (each $1 \mathrm{H}$, each dd, $J_{\mathrm{ab}}=1.0, J_{\mathrm{ac}}=11.7, J_{\mathrm{bc}}=16.7 \mathrm{~Hz}$, vinyl protons), and $6.7-7.9 \mathrm{ppm}(4 \mathrm{H}, \mathrm{AB}$ quartet-like, ArH).

An isomeric mixture of 3-[3-(o- and p-ethylphenyl)-2-oxapropyl]-3-methyloxetane (13b). This was obtained in $79 \%$ yield by phasetransfer catalytic reaction of 1 with a 3:7 molar mixture of $o$ - and $p$-ethylbenzyl chlorides in the same way as for the preparation of 3-(3-phenyl- 2-oxapropyl)-3-methyloxetane (13a): ${ }^{5}$ bp $81-$ $85^{\circ} \mathrm{C}$ (5.3-6.7 pa); IR (neat) 1095 (acyclic ether), 980 and 835 (cyclic ether), and 825 and $765 \mathrm{~cm}^{-1}$ (1,4- and 1.2-disubstituted benzene); ${ }^{1} \mathrm{H} \mathrm{NMR}\left(\mathrm{CDCl}_{3}\right) \delta=1.27(3 \mathrm{H}, \mathrm{t}, J=7.6 \mathrm{~Hz}$, $\left.\mathrm{CH}_{2} \mathrm{CH}_{3}\right), 1.37\left(3 \mathrm{H}, \mathrm{s}, \mathrm{CH}_{3}\right.$ on the oxetane ring), 2.65 and 2.71 (total $2 \mathrm{H}$, each q, $J=7.5 \mathrm{~Hz}, p$ - and $\left.o-\mathrm{CH}_{2} \mathrm{CH}_{3}\right), 3.55$ and 3.59 $\left(4 \mathrm{H} / 3\right.$ and $2 \mathrm{H} / 3$, each $\mathrm{s}, \mathrm{ArCH}_{2} \mathrm{OCH}_{2}-$ of $p$ - and $o$-isomers), 4.40 and 4.60 (each $2 \mathrm{H}, \mathrm{AB}$ quartet, $J=5.5 \mathrm{~Hz}, \mathrm{CH}_{2}$ of the oxetane ring), $4.53\left(2 \mathrm{H}, \mathrm{s}, \mathrm{CH}_{2} \mathrm{Ar}\right)$, and $7.1-7.4 \mathrm{ppm}(4 \mathrm{H}$, $\mathrm{m}, \mathrm{ArH})$. Thus the product $13 \mathbf{b}$ consists of $p$ - and $o$-ixomers in a $2: 1$ mole ratio.

Dry dichloromethane (DCM) and toluene as polymerization solvents were obtained by twice distilling pre-dried solvents over calcium hydride in an atmosphere of nitrogen. $p$-Butoxyacetanilide (25) was prepared by a reaction of $p-14$ with butyl bromide in $N, N$ dimethylformamide (DMF) in the presence of $\mathrm{K}_{2} \mathrm{CO}_{3}: \mathrm{mp} 111-112^{\circ} \mathrm{C}$ (from benzene) (lit. ${ }^{11} 112^{\circ} \mathrm{C}$ ). $o$-Butoxyacetanilide (27) was also obtained in a $79 \%$ yield in the same manner as that for the preparation of the $p$ isomer 25: bp $105-106^{\circ} \mathrm{C}(21 \mathrm{~Pa})$; IR (neat) 3450 and 3320 (amide NH), 1680 (amide $\mathrm{C}=\mathrm{O}$ ), 1250 (aromatic ether), and $750 \mathrm{~cm}^{-1}$ (1,2-disubstituted benzene); ${ }^{1} \mathrm{H}$ NMR $\left(\mathrm{CDCl}_{3}\right)$ $\delta=1.00\left(3 \mathrm{H}, \mathrm{t}, J=7 \mathrm{~Hz}, \mathrm{CH}_{3}\left(\mathrm{CH}_{2}\right)_{3}\right), 1.3-2.0$ $\left(4 \mathrm{H}, \quad \mathrm{m}, \quad \mathrm{CH}_{3}\left(\mathrm{CH}_{2}\right)_{2} \mathrm{CH}_{2}\right), 2.19 \quad(3 \mathrm{H}, \mathrm{s}$, $\left.\mathrm{CH}_{3} \mathrm{CO}\right), 4.04\left(2 \mathrm{H}, \mathrm{t}, J=6 \mathrm{~Hz}, \mathrm{CH}_{2} \mathrm{Ar}\right)$, 2.8-7.0 and 7.75 (total $4 \mathrm{H}$, each $\mathrm{m}, \mathrm{ArH}$ ), and $8.2-8.4 \mathrm{ppm}(1 \mathrm{H}, \mathrm{m}, \mathrm{CONH})$. Commercially available reagents were used without further purification for 1,4-dibromobutane (2a), 1,6-dibromohexane (2b), an isomeric mixture of chloromethylstyrenes (6), $p$-hydroxyacetophenone (9), $p$-hydroxybenzaldehyde (10), $p$ - and $o$-hydroxyacetanilides ( $p$-14 and $o-14)$, and other solvents.

\section{Polymerization}

A typical procedure is described for the preparation of a polystyrene-polyoxetane composite resin IB via a two-stage polymeriza- 
tion using $\mathbf{7 a}$ and $\mathbf{5}$ as cross-linking agents. In a test tube $(20 \phi \times 180)$ equipped with a ground-grass stopper, were placed $7 \mathbf{a}(3.37 \mathrm{~g}$, $13.2 \mathrm{mmol})$ and $5(0.72 \mathrm{~g}, 3.3 \mathrm{mmol})$, which were diluted to a total volume $7.5 \mathrm{~cm}^{3}$ with dry toluene. Azobisisobutyronitrile (AIBN) (81 $\mathrm{mg}$, corresponding to $3 \%$ molar respect to the total amount of styryl groups) was added to this solution, and the test tube was closed with a ground-gass stopper in an atmosphere of nitrogen after being degassed and flushed with dry nitrogen gas repeatedly. The test tube was heated at $80^{\circ} \mathrm{C}$ for $5 \mathrm{~h}$ and the contents were poured into a large amount of methanol to precipitate $3.23 \mathrm{~g}$ of poly(7a-co-5). This copolymer showed a mole ratio of $77: 23$ for monomeric units $7 \mathrm{a}$ and 5 by ${ }^{1} \mathrm{H}$ NMR spectroscopy. A mixture $(0.87 \mathrm{~g})$ of unchanged monomers 7a and 5 at a $84: 16$ mole ratio was recovered from the supernatant of the precipitation. Into a ground-grass test tube was placed $3.05 \mathrm{~g}$ of poly $(7 \mathbf{a}-\mathrm{co}-\mathbf{5})$ dried thoroughly in vacuo. To this copolymer dry DCM was added to dilute to a total volume $14 \mathrm{~cm}^{3}$ by using a hypodermic syringe under nitrogen atmosphere. The contents in the test tube were cooled at $-50^{\circ} \mathrm{C}$ and mixed with $0.03 \mathrm{~cm}^{3}$ of a $0.5 \mathrm{~mol} \mathrm{dm}^{-3}$ solution of a trifluoroboran $\left(\mathrm{BF}_{3}\right)$-tetrahydrofuran (THF) complex in DCM $(0.5 \mathrm{~mol} \%$ to the oxetanyl group). The test tube was held at $0^{\circ} \mathrm{C}$ for $20 \mathrm{~h}$. The gel product thus formed was washed with $10 \%$ aqueous methanol and methanol successively, and dried in vacuo to give a resin IB $(2.65 \mathrm{~g}$, $87 \%$ yield).

DVB-cross-linked polystyrene resins IIID-1 and IIID-2 carrying a terminal bromide in their side chains were prepared as described for the preparation of IIID-2. A styrene $7 \mathbf{a}(2.56 \mathrm{~g}$, $10.1 \mathrm{mmol}$ ), $2.51 \mathrm{mmol}$ of DVB (charged in $0.60 \mathrm{~g}$ of a commercial reagent with $55 \%$ purity for DVB), and AIBN (75 mg) were placed in a test tube $(20 \phi \times 180)$, and diluted with toluene to a total volume $5 \mathrm{~cm}^{3}$. Monomers were polymerized in the ordinary way. A product resin was crushed, well washed with methanol, and dried at $60^{\circ} \mathrm{C}$ in vacuo to obtain $3.04 \mathrm{~g}$ of IIID-2 with cross-linking level around $20 \mathrm{~mol} \%$ of DVB.

\section{Polymer Reactions of the Pendant Functional Groups}

Substitution Reaction of Pendant Bromide with Phenols; Typical Procedure. Poly(7a) $(0.931 \mathrm{~g}$, containing $3.65 \mathrm{mmol}$ of the pendant bromide) was heated with phenol $p-14(0.71 \mathrm{~g}$, $4.70 \mathrm{mmol})$ and anhydrous $\mathrm{K}_{2} \mathrm{CO}_{3}(0.65 \mathrm{~g})$ in DMF $\left(15 \mathrm{~cm}^{3}\right)$ at $80^{\circ} \mathrm{C}$ for $10 \mathrm{~h}$ with magnetic stirring. The DMF was evaporated and the residue poured into water $\left(50 \mathrm{~cm}^{3}\right)$. The precipitated polymer was collected by filtration, washed with water and methanol, and dried at $50^{\circ} \mathrm{C}$ in vacuo to give $0.867 \mathrm{~g}$ of a product polymer $p$-15a.

Hydrolysis of the Pendant Acetylamino Group with Hydrochloric Acid; Typical Procedure. p-15a $(0.647 \mathrm{~g}$, containing $1.58 \mathrm{mmol}$ of the residual amide group) was heated in $4 \mathrm{~N} \mathrm{HCl}$ $\left(20 \mathrm{~cm}^{3}\right)$ and 1,4 -dioxane $\left(20 \mathrm{~cm}^{3}\right)$ at $80^{\circ} \mathrm{C}$ for $5 \mathrm{~h}$. The solvent was evaporated and $10 \%$ aqueous $\mathrm{NaOH}\left(50 \mathrm{~cm}^{3}\right)$ was added to the residue. The product, polymer $p$-16a, was filtered, washed with water and methanol, and dried at $50^{\circ} \mathrm{C}$ in vacuo (yield, $0.476 \mathrm{~g}$ ).

Azo Coupling Reaction of the Pendant Anilino Group; Typical Procedure. Polymer $p$-16a $(0.132 \mathrm{~g}, 0.36 \mathrm{mmol}$ of the anilino residue $)$ was swollen with chloroform $\left(1 \mathrm{~cm}^{3}\right)$ overnight. $3 \mathrm{~N}$ $\mathrm{HCl}\left(20 \mathrm{~cm}^{3}\right)$ was added to the gelatious polymer which it was left standing for $3 \mathrm{~h}$. After removing the supernatant by decantation, the residual polymer was swollen with $3 \mathrm{~N} \mathrm{HCl}$ $\left(3 \mathrm{~cm}^{3}\right)$ and ethanol $\left(3 \mathrm{~cm}^{3}\right)$ and to the polymer was added an $1 \mathrm{~N}$ aqueous $\mathrm{NaNO}_{2}$ solution $\left(1 \mathrm{~cm}^{3}\right)$ with ice-cooling. After being left at $5^{\circ} \mathrm{C}$ for $30 \mathrm{~min}, o$-chlorophenol $(0.1 \mathrm{~g}, 0.78 \mathrm{mmol})$ dissolved in $2.5 \mathrm{~N} \mathrm{NaOH}\left(10 \mathrm{~cm}^{3}\right)$ was poured into the polymeric diazonium chloride below $5^{\circ} \mathrm{C}$, to obtain a reddish brown polymer. After this polymer was washed with water and stirred in refluxing methanol for $6 \mathrm{~h}$, a polymeric dye 17a was collected by filtration (yield, $0.126 \mathrm{~g}$ ). 
Reduction of the Pendant Carbonyl Groups with $\mathrm{NaBH}_{4}$; Typical Procedure. Into 19 $(0.806 \mathrm{~g}, 1.08 \mathrm{mmol}$ of the benzaldehyde residue) suspended in ethanol $\left(50 \mathrm{~cm}^{3}\right)$ was added $\mathrm{NaBH}_{4}(47 \mathrm{mg}, 1.3 \mathrm{mmol})$ below $5^{\circ} \mathrm{C}$. This mixture was stirred at $50^{\circ} \mathrm{C}$ for $2 \mathrm{~h}$. The product polymer was collected by filtration and washed with $10 \%$ aqueous acetic acid and methanol successively. $0.767 \mathrm{~g}$ of dried polymer 21 was obtained.

Cyanoethylation of the Pendant Benzyl Alcohol. The polymer $21(0.736 \mathrm{~g})$ was stirred with acrylonitrile $\left(15 \mathrm{~cm}^{3}\right)$ and $5 \% \mathrm{NaOH}(0.1$ $\mathrm{cm}^{3}$ ) for $1.5 \mathrm{~h}$ at refluxing temperature. After being neutralized with acetic acid, the contents were heated with added acetone $\left(30 \mathrm{~cm}^{3}\right)$ for 30 min under reflux. The product polymer was collected by filtration and washed successively with hot acetone, ether, water, methanol, and ether. Dried polymer $22(0.759 \mathrm{~g})$ was obtained.

Conversion of the Pendant Bromide to the Acetoxyl Group Followed by Alkaline Hydrolysis of the Ester. The polymer IIA-2 (1.019 g, $2.15 \mathrm{mmol}$ of the bromide group) was heated with powdered potassium acetate (KOAc) $(0.95 \mathrm{~g}, 9.8 \mathrm{mmol})$ in benzene $\left(15 \mathrm{~cm}^{3}\right)$ in the presence of tetrabutylammonium bromide (TBAB) $(0.09 \mathrm{mmol})$ for $5 \mathrm{~h}$ with stirring under reflux. Product polymer $\mathbf{2 3}$ was collected and washed successively with water, benzene, and methanol, and dried in vacuo (yield, $0.861 \mathrm{~g}$ ). The polymer $23(0.763 \mathrm{~g})$ was stirred in $2 \mathrm{~N}$ $\mathrm{NaOH}$ and methanol (each $\left.10 \mathrm{~cm}^{3}\right)$ at refluxing temperature for $4 \mathrm{~h}$. Product polymer 24 was washed with water and methanol successively, and dried in vacuo (yield, $0.589 \mathrm{~g}$ ).

\section{Phase-Transfer Catalytic Reactions Using Poly- meric PTCs}

Catalyses were carried out in the same way as in our previous reports. ${ }^{7,8}$ Products yields were determined by gas chromatography (GLPC) for aliquots withdrawn from a reaction mixture at specified times, and plotted against time.

\section{Measurements}

GLPC analysis of the products was performed in a Shimadzu GC 8A apparatus: grass column $(3.3 \phi \times 1 \mathrm{~m})$ packed with Silicone High Vacuum Grease (30\%)/Celite (80-100 mesh); carrier gas, $\mathrm{He}\left(66 \mathrm{~cm}^{3} \mathrm{~min}^{-1}\right)$; temp, $210^{\circ} \mathrm{C}$. IR spectra were recorded on a JASCO A-202 spectrometer, and ${ }^{1} \mathrm{H}$ NMR on a $100 \mathrm{MHz}$ instrument (JEOL FT-100S) using $\mathrm{CDCl}_{3}$ as the solvent and TMS as the internal standard at $25^{\circ} \mathrm{C}$. Gel permeation chromatography (GPC) was performed using G4000H8 and G2500HXL (each $7.8 \phi \times 300$, TOSHO) arranged in a series and THF as the eluent $\left(0.8 \mathrm{~cm}^{3} \mathrm{~min}^{-1}\right)$.

\section{RESULTS AND DISCUSSION}

\section{Preparation of Polymers}

Styrene derivative $7 \mathbf{a}$ with a 5-bromo-1oxapentyl side chain at the para position was prepared via the synthetic route shown in Scheme 2. A crude alcohol, obtained by a $\mathrm{NaBH}_{4}$-reduction of ketone 11a, was heated to give the required product $7 \mathbf{a}$ in a $68 \%$ isolated yield. In the same way $7 \mathbf{b}$ was also isolated in $72 \%$ yield. The preceding report described that $7 \mathbf{b}$ was prepared in a $27 \%$ yield via a reaction between $p$-hydroxystyrene and 2b using $\mathrm{K}_{2} \mathrm{CO}_{3}$ as a $\mathrm{HBr}$-trapping base in acetone to obtain DVB-cross-linked polystyrene resins by radical polymerization with AIBN. ${ }^{4}$ In our present report, the polymerizations of $\mathbf{7 a}$ and $\mathbf{7 b}$ were investigated by several methods. AIBN-initiated polymerizations of $7 \mathbf{a}$ and $7 \mathbf{b}$ in toluene at $80^{\circ} \mathrm{C}$ gave, respectively, their homopolymers poly(7a) and poly $(7 \mathbf{7 b})$ with molecular weights $\left(\bar{M}_{n}\right) 45000$ and 16000 , although considerable amounts of unchanged monomers were recovered. The styryl groups of $\mathbf{5}$ were susceptible to radical polymerizations with or without 7a, 7b, and 6 (Table I). Monomeric unit fractions of a product copolymer were estimated based on relative integral intensity for ${ }^{1} \mathrm{H}$ NMR signals of the corresponding monomeric units. An 
Table I. Preparation of uncross-linked polymers by AIBN-initiated radical polymerization in toluene at $80^{\circ} \mathrm{C}$ for $6 \mathrm{~h}$

\begin{tabular}{|c|c|c|c|c|c|c|c|}
\hline \multirow{3}{*}{$\frac{\text { Monomer }}{\text { (Mole ratio) }}$} & \multirow{3}{*}{$\frac{\mathrm{AIBN}}{\mathrm{mol} \%}$} & \multirow{3}{*}{$\frac{[\mathrm{M}]_{0}^{\mathrm{a}}}{\mathrm{mol} \mathrm{dm^{-3 }}}$} & \multicolumn{4}{|c|}{ Product polymer } & \multirow{3}{*}{$\begin{array}{c}\text { Recovery } \\
\text { of } \\
\text { monomer } / \%\end{array}$} \\
\hline & & & \multirow[b]{2}{*}{ Name } & \multirow{2}{*}{$\frac{\text { Yield }^{\mathrm{b}}}{\%}$} & \multirow{2}{*}{$\frac{\text { Monomeric unit }}{{\text { (Mole ratio })^{c}}^{c}}$} & \multirow{2}{*}{$\begin{array}{c}10^{-4} \times \\
\bar{M}_{n}^{\mathrm{d}}\end{array}$} & \\
\hline & & & & & & & \\
\hline $7 \mathbf{a}$ & 1 & 2.5 & - & 59 & $7 \mathbf{a}$ & 4.50 & 26 \\
\hline $7 \mathbf{a}$ & 3 & 2.2 & Poly $(7 \mathbf{a})$ & 76 & $7 \mathbf{a}$ & 1.35 & 24 \\
\hline $7 \mathbf{a} / \mathbf{5}(80: 20)$ & 3 & 2.2 & $\operatorname{Poly}(7 \mathbf{a}-c o-5)$ & 79 & $\mathbf{7 a / 5}(77: 23)$ & 1.30 & $20(84: 16)$ \\
\hline $7 \mathrm{~b}$ & 3 & 1.2 & Poly $(7 b)$ & 73 & $7 \mathrm{~b}$ & 1.56 & 26 \\
\hline $\mathbf{6 / 5}(59: 41)$ & 2 & 2.0 & $\operatorname{Poly}(6-c o-5)$ & 73 & 6/5 (64:36) & 1.80 & $18(46: 54)$ \\
\hline 5 & 1 & 2.4 & Poly(5)-D & 65 & 5 & n.d $d^{f}$ & 23 \\
\hline 5 & $0.5^{\mathrm{g}}$ & 2.7 & Poly(5)-C & 100 & 5 & n.d $\mathrm{d}^{\mathrm{f}}$ & 0 \\
\hline $13 a$ & $0.5^{\mathrm{g}}$ & 3.0 & Poly(13a) & 96 & 13a & 12.0 & 0 \\
\hline 13b & $0.5^{\mathrm{g}}$ & 3.4 & Poly (13b) & 98 & 13b & 22.0 & 0 \\
\hline
\end{tabular}

a A total concentration of monomers charged at beginning of polymerization.

b Based on weight of the product polymer obtained by reprecipitation with a toluene-methanol system.

c Mole ratio of monomeric units in the product polymer was calculated from integral intensity by ${ }^{1} \mathrm{H}$ NMR spectroscopy.

d Determined by GPC using a calibration curve based on $\bar{M}_{n}$ s of standard polystyrenes.

e Oligomers soluble in toluene-methanol $(1: 9, \mathrm{v} / \mathrm{v})$ but insoluble in methanol were also obtained as other products. Value in parentheses indicates the mole ratio of recovered monomers for $7 \mathbf{a} / 5$ or $6 / 5$ and was determined by ${ }^{1} \mathrm{H}$ NMR spectroscopy.

f Note determined.

g Cationic ring-opening polymerization was carried out in $\mathrm{DCM}$ at $0^{\circ} \mathrm{C}$ for $20 \mathrm{~h}$ with a $\mathrm{BF}_{3} \mathrm{THF}$ initiator $(0.5 \mathrm{~mol} \%)$ in place of AIBN.

oxetanyl residue of the resultant polymers poly(5)-D, poly(7a-co-5), and poly(6-co-5) were further polymerized with a $\mathrm{BF}_{3} \mathrm{THF}$ initiator to form insoluble polystyrene-polyoxetane composite resins carrying the alkyl bromide or benzylic chloride at the side chain-end of the polystyrene main chain. In these postpolymerizations with the cationic initiator, $\mathbf{3}$ and oxetane (12) were used as comonomers. The use of 12 may be help to modifying the characters of the resin, such as softness, swellability, and hydrophilicity. This procedure of a two-stage polymerization is designated Method B in the present article. The other polystyrene-polyoxetane composite resin synthesis, Method A, was also carried out via the inverted polymerization stage for Method B. Prepolymers of Method A poly(5)-C, poly(3-co-5), and poly(12-co-5) were prepared by cationic ring-opening polymerization with a $\mathrm{BF}_{3}$ THF initiator in toluene or DCM at $0^{\circ} \mathrm{C}$. These prepolymers in toluene were directly used in the post-polymerization without isolating them, since they did not contain any unchanged monomers in the post-polymerization mixture. For instance, the ${ }^{1} \mathrm{H}$ NMR spectrum of an aliquot, withdrawn from the resultant mixture of a cationic ring-opening copolymerization between 12 and 5 in DCM for $20 \mathrm{~h}$, did not indicate signals assignable to protons of the oxetane ring of charged monomers around $\delta 4.2-4.7 \mathrm{ppm}$. Monomeric unit fractions of copolymers thus obtained were also calculated in the same way as above. Although $\bar{M}_{n}$ s of these prepolymers were not measured, $\bar{M}_{n}$ s of model polymers poly(13a) and poly(13b) for prepolymers by Method A were 120000 and 220000, respectively. In each radical polymerization at the 2 nd stage of Method A, however, unchanged monomers 
were also recovered in considerable amounts. Monomeric unit fractions in resins obtained by Method A, therefore, were corrected by subtracting the amount of the recovered monomer from that of the same monomer charged at the 2 nd stage. Such correction was not required for determining monomeric unit fractions of resins obtained at the 2nd stage of Method B, since the cationic ring-opening polymerization of oxetane derivatives proceeded almost quantitatively, as shown by the yields of poly(13a) and poly (13b), and the ${ }^{1} \mathrm{H}$ NMR spectrum of poly(12-co-5). In every case of Method B, moreover, unchanged monomers were not detected by GLPC for washings of the resultant resin and IR spectra of the resins hardly indicated absorption bands at 930 and
$830 \mathrm{~cm}^{-1}$ due to the cyclic ether of an oxetane ring. Therefore, the monomeric unit fractions of a resin obtained by Method B are assumed identical with a molar ratio among a comonomer charged at the 2nd stage and the monomeric units of a prepolymer. Bisoxetane 4- and DVB-cross-linked polymers were also prepared, respectively, by $\mathrm{BF}_{3} \mathrm{THF}-$ and AIBN-initiated polymerization methods, designated Methods C and D. The resins thus obtained are summarized in Table II. All resins were insoluble in ordinary solvents. Characteristic IR bands of resins were similar to those of polyoxetane-polystyrene composite resins prepared from $\mathbf{3}$ and $\mathbf{5}$ as described in detail in our previous paper. ${ }^{8}$ The composite resins must have at least cross-linkages of 1,3- and

Table II. Preparation of resins by Methods A-D

\begin{tabular}{|c|c|c|c|c|c|c|c|c|c|}
\hline \multirow{4}{*}{ Method $^{\mathrm{a}}$} & \multirow{2}{*}{\multicolumn{3}{|c|}{ Prepolymer ${ }^{\mathbf{b}}$ or monomer }} & \multirow{2}{*}{\multicolumn{2}{|c|}{ Comonomer $^{d}$}} & \multicolumn{4}{|c|}{ Product resin } \\
\hline & & & & & & \multicolumn{3}{|c|}{ Monomeric unit } & \multirow{2}{*}{ Yield $^{\mathrm{f}}$} \\
\hline & \multirow[t]{2}{*}{$(\text { Mole ratio })^{\mathrm{c}}$} & & \multirow[t]{2}{*}{ wt g ${ }^{-1}$} & & \multirow[t]{2}{*}{$\mathrm{wtg}^{-1}$} & \multirow[t]{2}{*}{ Name } & \multirow{2}{*}{\multicolumn{2}{|c|}{$(\text { Mole ratio })^{\mathrm{e}}$}} & \\
\hline & & & & & & & & & $\%$ \\
\hline A & Poly(5)-C & & 0.43 & $7 \mathbf{a}$ & 2.02 & IA 1 & $7 a / 5$ & $(77: 23)$ & $70(26)$ \\
\hline B & Poly $(7 \mathbf{a}-c o-5)$ & $(77: 23)$ & 3.05 & - & - & IB & $7 a / 5$ & $(77: 23)$ & 87 \\
\hline $\mathrm{A}^{\mathrm{h}}$ & Poly (12-co-5) & $(64: 36)$ & 2.36 & $7 a$ & 1.39 & IIA-1 & $7 a / 12 / 5$ & $(21: 49: 30)^{\mathrm{g}}$ & 83 \\
\hline $\mathrm{A}^{\mathrm{h}}$ & Poly(12-co-5) & $(44: 56)$ & 1.14 & $7 \mathbf{a}$ & 1.39 & IIA-2 & $7 a / 12 / 5$ & $(39 .: 30: 31)^{\mathbf{g}}$ & 100 \\
\hline $\mathrm{D}$ & $7 a$ & & 2.15 & DVB & 0.06 & IIID-1 & 7a/DVB & $(93: 7)$ & $71(31)$ \\
\hline $\mathrm{D}$ & $7 \mathbf{a}$ & & 2.56 & DVB & 0.60 & IIID-2 & $7 \mathbf{a} / \mathrm{DVB}$ & $(80: 20)$ & 100 \\
\hline A & Poly(5)-C & & 0.95 & $7 b$ & 4.64 & IVA & $7 b / 5$ & $(69: 31)$ & $62(41)$ \\
\hline$B^{i}$ & Poly (6-co-5) & $(64: 36)$ & 1.06 & - & - & VB & $6 / 5$ & $(64: 36)$ & 98 \\
\hline A & Poly $(12-c o-5)$ & $(50: 50)$ & 1.92 & 6 & 1.52 & VIA & $6 / 12 / 5$ & $(41: 29: 30)$ & 92 \\
\hline B & Poly $(6-c o-5)$ & $(64: 36)$ & 1.06 & 12 & 0.13 & VIB & $6 / 12 / 5$ & $(47: 27: 26)$ & 94 \\
\hline A & Poly(3-co-5) & $(80: 20)$ & 4.71 & - & - & VIIA & $3 / 5$ & $(80: 20)$ & 84 \\
\hline$B^{i}$ & Poly(5)-D & & 0.63 & 3 & 2.74 & VIIB & $3 / 5$ & $(80: 20)$ & 91 \\
\hline $\mathrm{C}^{\mathrm{i}}$ & 3 & & 7.49 & 4 & 2.05 & VIIIC & $3 / 4$ & $(80: 20)$ & 93 \\
\hline$一^{j}$ & $\operatorname{Poly}(3-c o-5)$ & $(63: 37)$ & 3.75 & DVB & 0.04 & IXA & $3 / 5 / \mathrm{DVB}$ & $(63: 36: 1)$ & 83 \\
\hline
\end{tabular}

a See Scheme 3 for Methods A-D.

b Polymers were obtained by pre-polymerization.

c Mole ratio of monomeric units in a prepolymer determined by ${ }^{1} \mathrm{H}$ NMR spectroscopy.

d Comonomers were used in Method C or D, or at the 2nd stage of Method A or B.

e Mole ratio was calculated from the monomeric unit ratio of a charged prepolymer and amount of unchanged comonomer.

f Based on weight of the resin obtained. Values in parentheses indicate recovery as percentage for $7 \mathbf{a}$ or $7 \mathbf{b}$.

g Mole ratios were calculated from the following elemental analysis values: $\mathrm{C}, 66.69 \% ; \mathrm{H}, 7.86 \% ; \mathrm{Br}, 11.62 \%$ for IIA-1, and C, $64.34 \%$;, $7.22 \%$; Br, $16.64 \%$ for IIA-2.

${ }^{\mathrm{h}}$ DCM used in place of toluene as the solvent of the pre-polymerization.

i DCM used in the post-polymerization.

j Obtained by suspension polymerization according to our previous method (ref 8). 
1,4-phenylene-2-oxatrimethylenes between the polystyrene and polyoxetane main chains. Polystyrene and polyoxetane chains, or their oligomeric chains may be produced in a resin in the form of cross-linking, grafting, or looping segments, presumably depending on the copolymerizabilities of monomers and preparation method of the resin. Complicated structures of polymer networks in a resin are represented as a symbol $(P \sim$ in this article.

Chemical Modifications of Resins Using the Pendant Alkyl Bromide as an Original Starting Substrate in Synthetic Routes 4A, $4 B$, and $4 C$ by Polymer Reaction

Chemical reactions of a terminal bromine atom of the 2-oxahexamethylene spacer of such polyoxetane resins as VIIIC were previously reported by using KOAc, amines, and alcohols as a nucleophilic reagent. ${ }^{12}$ These substitution reactions gave the required product polymers with satisfactorily high degrees of functionalization (D.F) in fairly good yields. Chemical reactions of the bromide at the 1-oxapentamethylene spacer-end of the 7a unit in a resin are also investigated in this study using phenols 14, 9, and 10 and KOAc as nucleophiles to give several functional groups regarded as key substituents for designing various functionalized polymers. The chemical reactions of the pendant bromide are outlined in Schemes 4A-C.

Para-substituted phenoxyl residues of $p$ $15 \mathbf{a}-\mathbf{c}, o-15,18$, and 19 were introduced at the side chain-ends of polymers by substitution reactions of the terminal bromide of uncrossand cross-linked polymers with the corresponding phenols in $\mathrm{DMF}$ at $80^{\circ} \mathrm{C}$ in the presence of anhydrous $\mathrm{K}_{2} \mathrm{CO}_{3}$. The pendant residues thus linked to the polymeric supports were

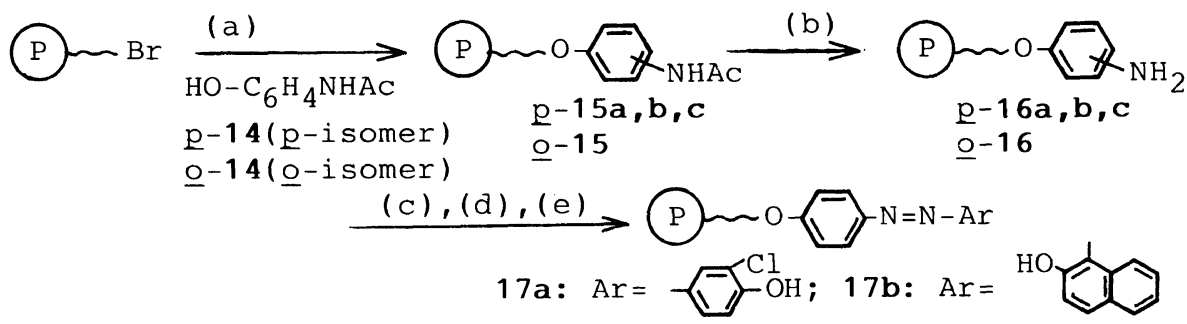

Scheme 4A. Derivatization from a pendant bromide. Reagents and conditions: (a) $p-14$ or $o-14, \mathrm{~K}_{2} \mathrm{CO}_{3}$, DMF, $80^{\circ} \mathrm{C}$; (b) $4 \mathrm{~N} \mathrm{HCl}, 1$,4-dioxane, $80^{\circ} \mathrm{C}$; (c) $1 \mathrm{~N} \mathrm{NaNO}_{2}$, conc $\mathrm{HCl}$; (d) ArOH, $\mathrm{NaOH}$; (e) methanol, reflux.

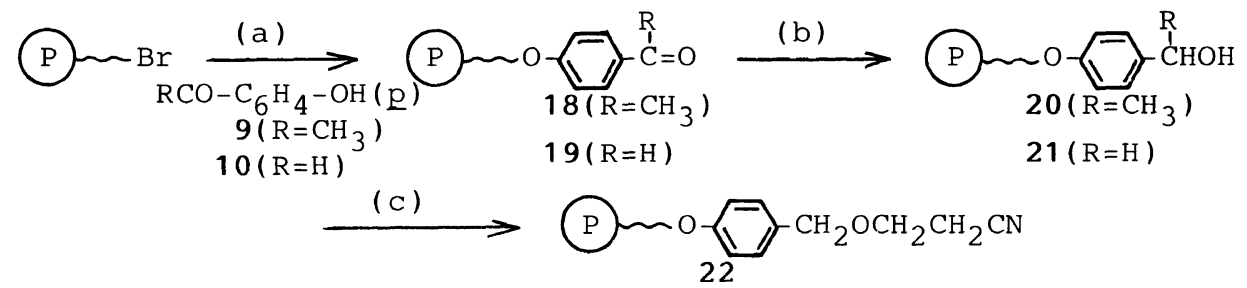

Scheme 4B. Derivatization from a pendant bromide. Reagents and conditions: (a) 9 or $10, \mathrm{~K}_{2} \mathrm{CO}_{3}$, DMF, $80^{\circ} \mathrm{C}$; (d) $\mathrm{NaBH}_{4}$, ethanol, $50^{\circ} \mathrm{C}$; (c) $\mathrm{CH}_{2}=\mathrm{CHCN}, 5 \% \mathrm{NaOH}$, reflux.

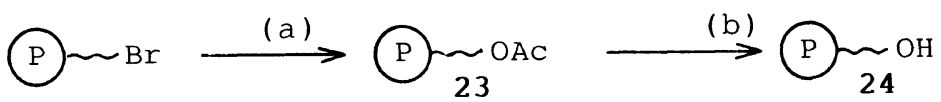

Scheme 4C. Derivatization from a pendant bromide. Reagents and conditions: (a) KOAc, TBAB, benzene, $80^{\circ} \mathrm{C}$; (b) $2 \mathrm{~N} \mathrm{NaOH}$-methanol $(1: 1, \mathrm{v} / \mathrm{v})$, reflux. 
confirmed on the basis of IR and/or ${ }^{1} \mathrm{H}$ NMR spectra and elemental analysis values for the product polymers.

To obtain more detailed information on the structures of insoluble polymers, soluble polymers $p$-15a and $o-15$, prepared from uncross-linked poly(7a) with $p-14$ or $o-14$, were subjected to ${ }^{1} \mathrm{H}$ NMR spectroscopic measurements, since $p$-15a was soluble in dimethylsulfoxide (DMSO) and $o-15$ was soluble in chloroform and other ordinary solvents. $\mathrm{A}^{1} \mathrm{H}$ NMR spectrum of $p$-15a in DMSO- $d_{6}$ is shown in Figure 1 along with that of $p$-butoxyacetanilide (25) in the same solvent. Protons $\mathrm{H}^{\mathrm{a}}$ to $\mathrm{H}^{\mathrm{f}}$ are assigned to the corresponding signals (a) to (f) in the spectrum (A) resembling the spectrum (B) of 25, a model compound for $p$-15a. The amide proton $\mathrm{H}^{\mathrm{a}}$ resonates at $\delta 9.81 \mathrm{ppm}$ in considerably low magnetic field, due to hydrogen-bonding interaction between the amide protons and DMSO solvent. The amide protons of 25 also resonate at $\delta 9.88 \mathrm{ppm}$ in DMSO- $d_{6}$. The relative integral intensity of each proton of $p-\mathbf{1 5 a}$ is reasonable compared with the calculated one. In the spectrum of $p$-15a, the integral intensity of a signal at $\delta 3.36 \mathrm{ppm}$ due to water is considerably strong relative to that at $\delta 2.57 \mathrm{ppm}$ due to protons of an undeuterated methyl group contained in a commercially available DMSO- $d_{6}$ solvent. In the spectrum of $\mathbf{2 5}$, however, a relative intensity ratio for protons of the contained water to those of the undeuterated methyl group is

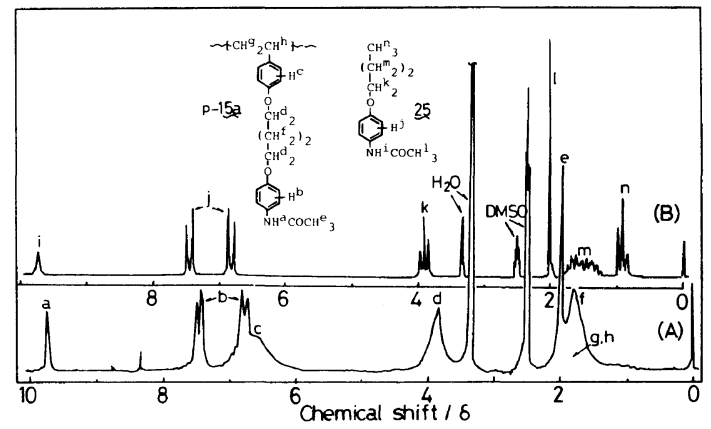

Figure 1. ${ }^{1} \mathrm{H}$ NMR spectra of (A) $p$-15a and (B) $p$-butoxyacetanilide (25) in DMSO- $d_{6}$. similar to the corresponding intensity ratio for the used solvent; the DMSO- $d_{6}$ itself contained water as a contaminant. This suggests that $p$-15a could hold a certain amount of water in its polymer matrices even after being dried at $60^{\circ} \mathrm{C}$ in vacuo for $8 \mathrm{~h}$, while the low-molecularweight model compound $\mathbf{2 5}$ hardly adsorbes extra water molecules. Presumably, this is bacause intermolecular hydrogen-bonding of the immobilized acetanilide residue is restricted in sterically crowded polystyrene materices. The acetanilide residue may be stabilized by hydrogen-bonding with an adequate amount of water.

Signals due to olefinic protons for $p$-15a are not observed at $\delta 5-6 \mathrm{ppm}$. In fact, terminal olefinic protons of 3-(2-oxa-5-hexenyl)-3methyloxetane (26) in $\mathrm{CDCl}_{3}$ indicate a complicated $\mathrm{ABC}$ coupling mode at $\delta 4.9-6.3$ ppm. Thus, that an elimination reaction of the pendant terminal bromide of poly(7a) does not occur during reaction with phenol $p$-14 in the presence of $\mathrm{K}_{2} \mathrm{CO}_{3}$ in DMF at $80^{\circ} \mathrm{C}$.

In the ${ }^{1} \mathrm{H}$ NMR spectrum of $o-15$ in $\mathrm{CDCl}_{3}$ (Figure 2), no signal due to water was found around $\delta 5 \mathrm{ppm}$, showing that $o-\mathbf{1 5}$ did not adsorbed such extra water molecules. A signal due to water which was thereafter added to the above ${ }^{1} \mathrm{H}$ NMR sample appeared at $\delta 4.8$ ppm. In the ${ }^{1} \mathrm{H}$ NMR spectrum (D) of $o$ butoxyacetanilide (27) being a model com-

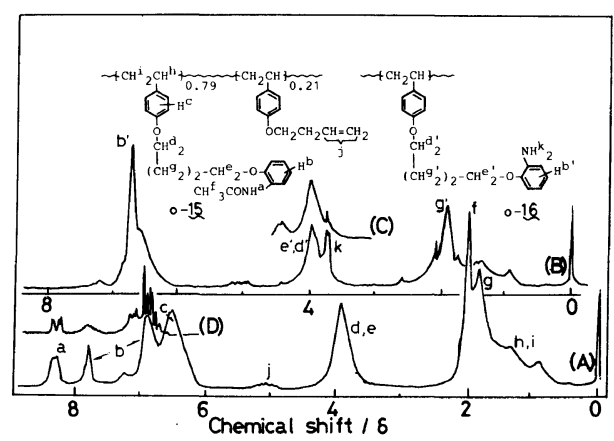

Figure 2. ${ }^{1} \mathrm{H}$ NMR spectra of (A) $o-15$, (B) $o-16$, (C) $o$-16 after treating it with $\mathrm{D}_{2} \mathrm{O}$, and (D) $o$-butoxyacetanilide (27). Spectra (C) and (D) are presented, respectively, in regions around $\delta 3-4.5$ and $6-9 \mathrm{ppm}$. 
pound for a pendant group of $0-15$, some of aromatic protons of $\mathbf{2 7}$ indicated a broad signal around $\delta 7.75 \mathrm{ppm}$ and similarly $\boldsymbol{o}-\mathbf{1 5}$ showed a signal at $\delta 7.8 \mathrm{ppm}$ in its ${ }^{1} \mathrm{H}$ NMR spectrum (A). These signals at lower magnetic fields may be assignable to the aromatic proton closest to the ether oxygen atom hydrogen-linked with the amide proton. The IR spectrum of 27 also showed a sharp band at $3450 \mathrm{~cm}^{-1}$ due to amide protons, which do not hydrogen-bond to each other, and a broad band at $3320 \mathrm{~cm}^{-1}$ due to intermolecularly hydrogen-bonding amido protons. Thus, the $o$-acetanilide residue of $o-15$ hardly requires extra water molecules for stabilizing the amide group in dried polymer matrices. Furthermore, the ${ }^{1} \mathrm{H}$ NMR spectrum of $o-15$ showed a broad signal (j) with a slight integral intensity at $\delta 4.7-5.4$ ppm. This showes the existence of terminal olefinic protons in $o-\mathbf{1 5}$, as described above for the ABC coupling mode of model compound 26. Such formation of the terminal olefinic linkage in the pendant side chain of $o-15$ is ascribable to an elimination reaction of the pendant terminal bromide of the starting polymer poly(7a). Therefore, on the basis of elemental analysis for the nitrogen atom of the product polymer, about $20 \mathrm{~mol} \%$ of the pendant bromide is subjected to the elimination reaction.

The pendant amide residues of polymers $p-15 a-c$ and $o-15$ were completely hydrolyzed by heating each polymer in $4 \mathrm{~N}$ aqueous $\mathrm{HCl}$ and 1,4-dioxane (1:1 in volume) at $80^{\circ} \mathrm{C}$ for $5 \mathrm{~h}$, as shown in IR spectra of products $p$-16a $-c$ and $o-16$, which indicated IR bands at 3350 and $3450 \mathrm{~cm}^{-1}$ due to the amino residue but no band at $1665 \mathrm{~cm}^{-1}$ due to the amido residue. Uncross-linked $p$-16 and $o-16$ were soluble in chloroform, and their structures were confirmed by ${ }^{1} \mathrm{H}$ NMR spectroscopy, as exemplified for $o-16$ in Figure 2. Polymer $o$-16 was soluble in methanol- $6 \mathrm{~N} \mathrm{HCl}(4: 1$ in volume) and reprecipitated by adding this solution into a large volume of ether. Monomeric unit fractions of the precipitated polymer $o-16$ in the form of a $\mathrm{HCl}$ salt in part were estimated on the basis of nitrogen and chlorine contents determined by elemental analysis. The formation of the anilino residue was confirmed by converting $p$-16a to a reddish brown polymeric dye 17a through diazotization of the aniline moiety of $p$-16a followed by an azo coupling reaction between the resultant polymeric diazonium and $o$-chlorophenol. This polymeric azo coupling product indicated at IR band at $2250 \mathrm{~cm}^{-1}$ due to an unchanged diazonium group which was appreciably observed even after the polymer was left to air at room temperature for 10 days. When the polymer was warmed in refluxing methanol, the unchanged diazonium was probably converted to the methoxyl group in the resultant polymer 17a. ${ }^{13}$ On the basis of elemental analysis for carbon, chlorine, and nitrogen of $17 \mathrm{a}, 70 \mathrm{~mol} \%$ of the pendant anilino residue of $p$-16a was diazotized and $30 \mathrm{~mol} \%$ of the resultant diazonium was consumed to give the pendant azo group, corresponding to a $21 \%$ conversion of the anilino moiety into the azo group. Similarly, the terminal bromide of insoluble cross-linked resins IB and IIA-1 was converted to the corresponding aniline derivatives though the formation of acetanilide moieties in the side chain-end of $p$-16b or $p$-16c. The aniline residue to $p$-16c was also changed to the azo group of 17b at low D.F with 2-naphthol.

Carbonyl groups of pendant benzaldehyde and acetophenone moieties were reduced with $\mathrm{NaBH}_{4}$ in ethanol within $2-5 \mathrm{~h}$, yielding the corresponding alcohols 20 and 21. The cyanoethylation of the hydroxyl group of $\mathbf{2 1}$ was examined with acrylonitrile in the presence of a catalytic amount of $5 \%$ aqueous $\mathrm{NaOH}$. Nitrogen content $2.06 \%$ determined by elemental analysis for 22 seems close to the theoretical value $1.75 \%$ required for the product polymer formed quantitatively through three reaction steps from the pendant bromide of the starting polymer IIA-1. The conversion of the pendant bromide of IIA-2 to an hydroxyl 
Table III. Polymer reactions of pendant substrates

\begin{tabular}{|c|c|c|c|c|c|c|}
\hline \multirow{2}{*}{\multicolumn{2}{|c|}{ Starting polymer }} & \multicolumn{5}{|c|}{ Product polymer } \\
\hline & & \multirow[b]{2}{*}{ Name } & \multirow[b]{2}{*}{ Anal. $/ \%$} & Functional group $X^{\mathrm{b}}$ & \multirow[b]{2}{*}{ Yield $/ g(\%)$} & \multirow[b]{2}{*}{ D.F. ${ }^{\mathrm{d}}$} \\
\hline Name & wt g ${ }^{-1}(\mathrm{mmol})^{\mathrm{a}}$ & & & (Mole fraction) & & \\
\hline Poly(7a) & $0.931(3.65)$ & $p-15 \mathbf{a}$ & $\begin{array}{ll}\mathrm{Br}, & 0.00 \\
\mathrm{~N}, & 3.43\end{array}$ & $\mathrm{OC}_{6} \mathrm{H}_{4}-\mathrm{HNAc}(1.00)$ & $0.867(58)[20]$ & 1.00 \\
\hline$p-15 a$ & $0.647(1.58)$ & $p-16 a$ & $\begin{array}{l}\mathrm{N}, \quad 3.82 \\
\mathrm{C}, \quad 73.54\end{array}$ & $\mathrm{OC}_{6} \mathrm{H}_{4}-\mathrm{NH}_{2}(1.00)$ & $0.476(82)[23]$ & 1.00 \\
\hline$p-16 \mathbf{a}$ & $0.132(0.36)$ & $17 \mathbf{a}$ & $\begin{array}{ll}\mathrm{Cl}, & 2.26 \\
\mathrm{~N}, & 3.41\end{array}$ & $\begin{array}{l}\mathrm{OC}_{6} \mathrm{H}_{4}-\mathrm{N}_{2} \mathrm{C}_{6} \mathrm{H}_{4}-(\mathrm{OH}) \mathrm{Cl}(0.21) \\
\mathrm{OC}_{6} \mathrm{H}_{4}-\mathrm{OMe}(0.49) \\
\mathrm{OC}_{6} \mathrm{H}_{4}-\mathrm{NH}_{2}(0.30)\end{array}$ & $0.126(110)^{\mathrm{e}}$ & 0.20 \\
\hline $\operatorname{Poly}(7 a)$ & $0.497(1.95)$ & 18 & $\mathrm{Br}, \quad 0.61$ & $\begin{array}{l}\mathrm{OC}_{6} \mathrm{H}_{4}-\mathrm{Ac}(0.98) \\
\mathrm{Br}(0.02)\end{array}$ & $0.446(74)$ & 0.98 \\
\hline 18 & $0.387(1.23)$ & 20 & n.d $\mathrm{d}^{\mathrm{f}}$ & $\begin{array}{l}\mathrm{OC}_{6} \mathrm{H}_{4}-\mathrm{CH}(\mathrm{OH}) \mathrm{Me}(0.77)^{\mathrm{g}} \\
\mathrm{OC}_{6} \mathrm{H}_{4}-\mathrm{Ac}(0.21) \\
\mathrm{Br}(0.02)\end{array}$ & $0.288(74)$ & 0.79 \\
\hline $\operatorname{Poly}(7 \mathbf{a})$ & $0.553(2.17)$ & $o-15$ & $\begin{array}{ll}\mathrm{Br}, & 0.00 \\
\mathrm{~N}, & 3.75\end{array}$ & $\begin{array}{l}\mathrm{OC}_{6} \mathrm{H}_{4}-\mathrm{NHAc}(0.79) \\
\mathrm{Ar}-\mathrm{OCH}_{2} \mathrm{CH}_{2} \mathrm{CH}=\mathrm{CH}_{2}{ }^{\mathrm{h}} \\
(0.21)\end{array}$ & $0.546(86)$ & 0.79 \\
\hline$o-15$ & $0.450(1.53)$ & $o-16$ & $\begin{array}{ll}\mathrm{Cl}, & 2.52 \\
\mathrm{~N}, & 3.91\end{array}$ & $\begin{array}{l}\mathrm{OCH}_{6} \mathrm{H}_{4}-\mathrm{NH}_{2}(0.71) \\
\mathrm{OCH}_{6} \mathrm{H}_{4}-\mathrm{NH}_{3} \mathrm{Cl}(0.08) \\
\mathrm{Ar}-\mathrm{OCH}_{2} \mathrm{CH}_{2} \mathrm{CH}=\mathrm{CH}_{2}{ }^{\mathrm{h}} \\
(0.21)\end{array}$ & $0.111(25)[10]$ & 1.00 \\
\hline IB & $0.501(1.55)$ & $p-15 b$ & $\begin{array}{ll}\mathrm{Br}, & 0.89 \\
\mathrm{~N}, & 3.18\end{array}$ & $\begin{array}{l}\mathrm{OC}_{6} \mathrm{H}_{4}-\mathrm{NHAc}(0.73) \\
\mathrm{Br}(0.04)\end{array}$ & $0.506(74)[8]$ & 0.95 \\
\hline$p-15 b$ & $0.399(0.90)$ & $p-16 b$ & $\mathrm{~N}, \quad 3.56$ & $\begin{array}{l}\mathrm{OC}_{6} \mathrm{H}_{4}-\mathrm{NH}_{2}(0.73) \\
\mathrm{Br}(0.04)\end{array}$ & $0.327(92)[7]$ & 1.00 \\
\hline IIA-1 & $1.002(1.43)$ & $p-15 c$ & $\begin{array}{ll}\mathrm{Br}, & 0.00 \\
\mathrm{~N}, & 1.51\end{array}$ & $\mathrm{OC}_{6} \mathrm{H}_{4}-\mathrm{NHAc}(0.21)$ & $0.949(72)[17]$ & 1.00 \\
\hline$p-15 \mathrm{c}$ & $0.908(0.98)$ & $p-16 c$ & $\mathrm{~N}, \quad 1.52$ & $\mathrm{OC}_{6} \mathrm{H}_{4}-\mathrm{NH}_{2}(0.2 \mathrm{l})$ & $0.826(91)[23]$ & 1.00 \\
\hline$p-16 c$ & $0.132(0.14)$ & $17 b$ & $\mathrm{~N}, \quad 1.53$ & $\begin{array}{l}\mathrm{OC}_{6} \mathrm{H}_{4}-\mathrm{N}_{2} \mathrm{C}_{10} \mathrm{H}_{6} \mathrm{OH} \\
\text { and other groups }\end{array}$ & 0.082 (n.d) & n.d \\
\hline IIA-1 & $0.855(1.24)$ & 19 & $\begin{array}{l}\mathrm{C}, \quad 74.23^{\mathrm{i}} \\
\mathrm{Br}, \quad 0.00\end{array}$ & $\mathrm{OC}_{6} \mathrm{H}_{4}-\mathrm{CHO}(0.21)$ & $0.847(93)$ & 1.00 \\
\hline 19 & $0.806(1.08)$ & 21 & n.d & $\mathrm{OC}_{6} \mathrm{H}_{4}-\mathrm{CH}_{2} \mathrm{OH}(0.21)$ & $0.767(96)$ & 1.00 \\
\hline 21 & $0.736(0.99)$ & 22 & $\mathrm{~N}, \quad 2.06$ & $\begin{array}{l}\mathrm{OC}_{6} \mathrm{H}_{4}-\mathrm{CH}_{2} \mathrm{O}-\left(\mathrm{CH}_{2}\right)_{2} \mathrm{CN} \\
(0.21)\end{array}$ & $0.759(94)$ & 1.00 \\
\hline IIA-2 & $1.019(2.15)$ & 23 & $\begin{array}{l}\mathrm{C}, \quad 72.51^{\mathrm{i}} \\
\mathrm{Br}, \quad 0.52\end{array}$ & $\begin{array}{l}\text { OAc }(0.38) \\
\operatorname{Br}(0.01)\end{array}$ & $0.861(89)$ & 0.98 \\
\hline 23 & $0.763(1.64)$ & 24 & n.d & $\mathrm{OH}(0.38) ; \mathrm{Br}(0.01)$ & $0.589(85)$ & 1.00 \\
\hline
\end{tabular}

a Values in parentheses indicate millimoles of pendant substrates of polystyrenes. Grain size of the polymers was in the region, 60-100 mesh.

b $\mathrm{X}$ represents functional group at the spacer-end of styryl-O $\left(\mathrm{CH}_{2}\right)_{4}-\mathrm{X}$ in modified polystyrene. Also see Scheme 4. Value in parentheses indicates mole fraction of a monomeric unit with functional group $\mathrm{X}$.

c Value in parentheses shows yield as percentage based on the theoretical amount of product polymer with indicated mole fraction. Value in brackets shows wt $\%$ of adsorbed water estimated by elemental analysis.

d Degree of functionalization (D.F) for main functional group.

e Obtained weight of product was heavier by $10 \%$ than the theoretical weight.

f Not determined.

${ }^{\mathrm{g}}$ Mole ratio between formed alcohol and unchanged ketone determined by ${ }^{1} \mathrm{H}$ NMR spectroscopy.

${ }^{\text {h }}$ See the text for these groups.

i Mole fractions estimated from bromine content. Calculated carbon contents required 74.27 and $72.95 \%$, respectively, for 19 and 23 with the indicated mole fractions. 
Table IV. Identification of modified polymers

\begin{tabular}{|c|c|}
\hline Polymer & IR bands and ${ }^{1} \mathrm{H}$ NMR signals ${ }^{\mathrm{a}}$ \\
\hline$p-15 \mathbf{a}-\mathbf{c}^{\mathbf{b}}$ & $\begin{array}{l}3400(\mathrm{NH}) ; 1665(\mathrm{C}=\mathrm{O}) ; 1240 \text { (aromatic } \\
\text { ether); } 1100 \text { (acyclic ether); } 825 \mathrm{~cm}^{-1} \\
\left(p-\mathrm{C}_{6} \mathrm{H}_{4}\right)\end{array}$ \\
\hline$p-16 a-c$ & $\begin{array}{l}3370,3460,1629\left(\mathrm{NH}_{2}\right) ; 1245 \text { (aromatic } \\
\text { ether, C-N); } 1100 \text { (acyclic ether); } 835 \\
\mathrm{~cm}^{-1}\left(p-\mathrm{C}_{6} \mathrm{H}_{4}\right)\end{array}$ \\
\hline$o-15^{\mathrm{d}}$ & $\begin{array}{l}3430(\mathrm{NH}) ; 1670(\mathrm{C}=\mathrm{O}) ; 1230 \text { (aromatic } \\
\text { ether); } 815\left(p-\mathrm{C}_{6} \mathrm{H}_{4}\right) ; 745 \mathrm{~cm}^{-1}\left(o-\mathrm{C}_{6} \mathrm{H}_{5}\right)\end{array}$ \\
\hline$o-16^{\mathrm{d}}$ & $\begin{array}{l}3400,3450,1615\left(\mathrm{NH}_{2}\right) ; 1245 \text { (aromatic } \\
\text { ether); } 1220(\mathrm{C}-\mathrm{N}) ; 1100 \text { (aceyclic ether); } \\
830\left(p-\mathrm{C}_{6} \mathrm{H}_{4}\right) ; 740 \mathrm{~cm}^{-1}\left(o-\mathrm{C}_{6} \mathrm{H}_{4}\right)\end{array}$ \\
\hline 18 & $\begin{array}{l}1680(\mathrm{C}=\mathrm{O}) ; 1255 \text { (aromatic ether); } \\
830 \mathrm{~cm}^{-1}\left(p-\mathrm{C}_{6} \mathrm{H}_{4}\right) . \delta=0.8-2.2\left(\mathrm{CH}_{2}\right) ; \\
2.5\left(\mathrm{COCH}_{3}\right) ; 3.7-4.2\left(\mathrm{OCH}_{2}\right) ; 6.3-6.8 \\
(\text { styryl } \mathrm{ArH}) ; 6.8-8.2 \text { ppm (AB-q like, } \\
\left.p-\mathrm{C}_{6} \mathrm{H}_{4}\right) .\end{array}$ \\
\hline 19 & $\begin{array}{l}2730,1690(\mathrm{CH}=\mathrm{O}) ; 1240 \text { (aromatic } \\
\text { ether); } 1100(\text { acyclic ether }) ; 830 \mathrm{~cm}^{-1} \\
\left(p-\mathrm{C}_{6} \mathrm{H}_{4}\right)\end{array}$ \\
\hline 20 & $\begin{array}{l}3400,1050(\mathrm{OH}) ; 1255 \text { (aromatic ether); } \\
830 \mathrm{~cm}^{-1}\left(p-\mathrm{C}_{6} \mathrm{H}_{4}\right) . \delta=1.5\left(\mathrm{~d}, \mathrm{CH}_{3}\right) \\
3.8-5.0(\mathrm{CH}) ; 6.3-6.8(\text { styryl } \mathrm{ArH}) \\
6.8-7.4 \mathrm{ppm}\left(\mathrm{AB}-\mathrm{q} \text { like, } p-\mathrm{C}_{6} \mathrm{H}_{4}\right)\end{array}$ \\
\hline 21 & $\begin{array}{l}3450,1040-1000(\mathrm{OH}) ; 1240(\text { aromatic } \\
\text { ether }) ; 1100 \text { (acyclic ether); } 830 \mathrm{~cm}^{-1} \\
\left(p-\mathrm{C}_{6} \mathrm{H}_{4}\right)\end{array}$ \\
\hline 22 & $\begin{array}{l}2250(\mathrm{CN}) ; 1240 \text { (aromatic ether); } 1100 \\
\text { (acyclic ether); } 825 \mathrm{~cm}^{-1}\left(p-\mathrm{C}_{6} \mathrm{H}_{4}\right)\end{array}$ \\
\hline 23 & $\begin{array}{l}1740,1240,1040 \text { (ester); } 1240 \text { (aromatic } \\
\text { ether); } 1100 \text { (acyclic ether); } 830 \mathrm{~cm}^{-1} \\
\left(p-\mathrm{C}_{6} \mathrm{H}_{4}\right)\end{array}$ \\
\hline 24 & $\begin{array}{l}3450,1050(\mathrm{OH}) ; 1250(\text { aromatic ether); } \\
1100(\text { acyclic ether }) ; 830 \mathrm{~cm}^{-1}\left(p-\mathrm{C}_{6} \mathrm{H}_{4}\right)\end{array}$ \\
\hline \multicolumn{2}{|c|}{$\begin{array}{l}\text { a Characteristic bands and signals used for identifying } \\
\text { product polymers. } \\
\text { b }{ }^{1} \mathrm{H} \text { NMR spectrum of } p \text {-15a is presented in Figure } 1 . \\
\text { c } \text { IR band due to polyoxetane segment in } p \text {-15c and } \\
p \text {-16c. } \\
\text { d }{ }^{1} \mathrm{H} \text { NMR spectra presented in Figure } 2 \text {. }\end{array}$} \\
\hline
\end{tabular}

group was achieved amoothly by a phasetransfer catalytic reaction using KOAc and TBAB in benzene followed by hydrolysis with a mixture of $2 \mathrm{~N}$ aqueous $\mathrm{NaOH}$ and methanol ( $1: 1$ in volume) at reflux temperature.

The results of polymer reactions are summarized in Table III and identification of the structures of product polymers thus obtained is shown in Table IV.
Quality of a Polyether Network of Supporting Polystyrene-Polyoxetane Composite Resins Compared with DVB-Cross-Linked Polystyrene Resins

As shown in the above-mentioned discussion, pendant acetoxyl and carbonyl groups, separated through 1-oxapolymethylene spacers linked at the styryl para position to the polystyrene-polyoxetane composite resins, smoothly reacted with ionic species $\mathrm{NaOH}$ or $\mathrm{NaBH}_{4}$ in aqueous or alcoholic solvents known to be poor solvents for DVB-cross-linked polystyrenes. In order to show some qualities of polystyrene-polyoxetane composite resins by comparing them with those of DBV-crosslinked polystyrene resins, these composite resins were used as polymeric supports immobilizing the pendant quaternary ammonium bromide of a polymeric PTC, since its catalytic activity is thought to be influenced by the quality and spacer length of polymeric supports. The polymeric PTCs in this study are summarized in Table V.

Softness of Polyether Networks. Several polymeric PTCs were examined in phasetransfer catalysis using 1 and 2a at a 1:3 mole ratio in $50 \% \mathrm{NaOH}$ and hexane in the presence of $3 \mathrm{~mol} \%$ of a pendant quaternary ammonium salt to 1 (Table VI).

When spacer-modified polymeric PTCs with the grain size of 60-100 mesh were used in catalysis at $78^{\circ} \mathrm{C}$, conversion of 1 to 3 in $75-80 \%$ yield was possible in each cases. These catalyzing abilities were hardly affected by the structure of a cross-linking agent, contained in mole fraction of up to $20-30 \%$ in the PTC, and by the preparation method of polymeric supports. An apparent formation rate of 3 decreased with decrease of reaction temperature from $78^{\circ} \mathrm{C}$ to $45^{\circ} \mathrm{C}$ through $65^{\circ} \mathrm{C}$ (No. 2 -4). Such influence of reaction temperature on the formation rate of $\mathbf{3}$ was also observed for catalyses using other polymeric PTCs. The catalytic activity of TBAB for the formation of 3 at $60^{\circ} \mathrm{C}$, however, seems comparable to those at $78^{\circ} \mathrm{C}$ with polymeric 
M. Motol et al.

Table V. Polymers used as phase-transfer catalyst ${ }^{\mathrm{a}}$

\begin{tabular}{|c|c|c|c|c|c|c|c|c|}
\hline \multirow{2}{*}{$\begin{array}{c}\text { PTC } \\
\text { name }^{\text {b }}\end{array}$} & \multicolumn{4}{|c|}{ Mole fraction } & \multirow{2}{*}{ D.F $F^{d}$} & \multirow{2}{*}{$\frac{\begin{array}{c}\text { Ammonium } \\
\text { group }\end{array}}{\mathrm{mmolg}^{-1}}$} & \multicolumn{2}{|c|}{ Anal./\% } \\
\hline & $\begin{array}{c}\mathrm{Z}^{-} \mathrm{Bu}_{3} \mathrm{~N}^{+}- \\
\mathrm{CH}_{2}-^{\mathrm{c}}\end{array}$ & $\mathrm{ZCH}_{2}-^{\mathbf{c}}$ & 12 & 5 & & & $\mathrm{Br}(\mathrm{Cl})$ & $\mathrm{N}$ \\
\hline IA-N & 0.77 & 0.00 & - & 0.23 & 1.00 & 1.32 & 10.60 & 1.85 \\
\hline IB-N & 0.75 & 0.02 & - & 0.23 & 0.98 & 1.45 & 11.88 & 2.04 \\
\hline IIA-IN & 0.20 & 0.01 & 0.49 & 0.30 & 0.96 & 0.75 & 6.23 & 1.05 \\
\hline IIA-2N & 0.32 & 0.07 & 0.30 & 0.31 & 0.83 & 0.80 & 7.70 & 1.12 \\
\hline IIID-1N & 0.81 & 0.12 & - & $0.07^{j}$ & 0.87 & 1.68 & 15.43 & 2.35 \\
\hline IIID-2N ${ }^{f}$ & 0.69 & 0.11 & - & $0.20^{\mathrm{j}}$ & 0.86 & 1.21 & 11.29 & 1.70 \\
\hline VIA-N & $0.21^{\mathrm{g}}$ & 0.20 & 0.29 & 0.30 & 0.51 & 1.11 & $(3.14)^{\mathrm{h}}$ & 1.56 \\
\hline VIB-N & $0.35^{\mathrm{g}}$ & 0.12 & 0.27 & 0.26 & 0.75 & 1.67 & $(4.57)^{\mathbf{h}}$ & 2.34 \\
\hline VIIA-N & 0.62 & 0.18 & - & 0.20 & 0.77 & 1.32 & 13.75 & 1.85 \\
\hline VIIB-N & 0.65 & 0.15 & - & 0.20 & 0.81 & 1.23 & 14.54 & 2.07 \\
\hline VIIIC-N & 0.52 & 0.28 & - & $0.20^{\mathrm{k}}$ & 0.66 & 1.23 & 14.85 & 1.73 \\
\hline$I X-N^{f, i}$ & $\mathrm{n} \cdot \mathrm{d}^{1}$ & $\mathrm{n} \cdot \mathrm{d}^{\mathrm{l}}$ & - & $\begin{array}{c}0.36^{\mathrm{k}} \\
/ 0.01^{\mathrm{j}}\end{array}$ & $\mathrm{n} . \mathrm{d}^{l}$ & 1.2 & $\mathrm{n} . \mathrm{d}^{1}$ & 1.69 \\
\hline
\end{tabular}

a Grain size of about $60-100$ mesh.

b Names of PTCs are related to names of polymeric supports in Table II, respectively, and letter $\mathrm{N}$ represents existence of pendant quaternary ammonium salt. Polymers were used as starting polymers for quaternizing pendant halide with $\mathrm{Bu}_{3} \mathrm{~N}$.

c Mole fractions of monomeric units with pendant quaternary ammonium halide or alkyl halide, where $Z$ is $\mathrm{Br}$ or Cl.

${ }^{d}$ Degree of functionalization (D.F) for quaternization reaction of pendant halide.

e Milimoles of pendant quaternary ammonium halide per $\mathrm{g}$ of dry polymeric PTC.

f Grain size of about 16-32 and 8-32 mesh for IIID-2N and IX-N, respectively.

g Fractions determined from carbon and nitrogen contents. Counternanions such as $\mathrm{OH}^{-}$, for $\mathrm{Z}^{-}$present besides the chloride anions.

${ }^{\text {h }}$ Structures of VIA-N and VIB-N required 7.96 and $8.01 \%$ for chlorine content, respectively, assuming chloride counteranions for all resultant quaternary ammonium cations.

i Obtained by the method previously reported (ref 8).

$\mathrm{j}$ DVB used in place of $\mathbf{5}$.

k Bisoxetane 4 used in place of 5 .

1 Not determined.

PTCs, although the catalysis with TBAB gave a slightly higher yield of $\mathbf{4}$ than with polymeric PTCs (No. 8). At higher reaction temperatures, networks of these polymeric supports may expand with more ease due to greater availability of thermal energy. In fact, an expanded polyether network of a polyoxetanebased PTC was observed as oily or gelatinous particles over the interface between organic and aqueous layers. ${ }^{7}$ Although such expansion of the DVB-cross-linked polymeric support is hardly expected for IIID-1N, its farily high catalytic activity may be ascribable to grinding particles of IIID-1N into those with smaller grain size (vide infra). A mole fraction of the monomeric unit $\mathbf{1 2}$ in a PTC apparently influences catalytic activity, as shown by comparing time-yield curves for 3 in catalyses using IIA-1N and IIA-2N, which contain 49 and $30 \mathrm{~mol} \%$ of the monomeric unit 12 , respectively, in $2 \%$ molar respect to 1 at $65^{\circ} \mathrm{C}$ $(\triangle$ and $O$ in Figure 3). The existence of segments from 12 in a PTC may be related to softness or expanding ability of the polymer network of the PTC, although the effects of the segments seem slight.

Influence of Cross-Linking DVB on Brittleness and Swellability of Polymeric Supports. In 
Polystyrene-Polyoxetane Composite Resins

Table VI. Phase-transfer catalyses between 1 and 2 a using polymeric PTCs ${ }^{\mathrm{a}}$

\begin{tabular}{|c|c|c|c|c|c|c|c|c|c|c|}
\hline \multirow{3}{*}{$\begin{array}{l}\text { Run } \\
\text { no. }\end{array}$} & \multirow{3}{*}{$\begin{array}{c}\text { PTC } \\
\text { Name }\end{array}$} & \multirow{3}{*}{$\underset{{ }^{\circ} \mathrm{C}}{\text { Temp }} /$} & \multicolumn{8}{|c|}{ Yields of 3 and $4 \%$} \\
\hline & & & \multirow{2}{*}{ Product } & \multicolumn{7}{|c|}{ Reaction time $/ \mathrm{h}$} \\
\hline & & & & 0.5 & 1.0 & 2.0 & 3.0 & 4.0 & 5.0 & 6.0 \\
\hline \multirow[t]{2}{*}{1} & IA-N & 78 & 3 & 55 & 63 & 68 & 71 & 74 & & \\
\hline & & & 4 & 3 & 3 & 5 & 6 & 7 & & \\
\hline \multirow[t]{2}{*}{2} & IB-N & 78 & 3 & 55 & 63 & 71 & 72 & 74 & 77 & \\
\hline & & & 4 & 4 & 5 & 5 & & 5 & 7 & \\
\hline \multirow[t]{2}{*}{3} & IB-N & 65 & 3 & 12 & 28 & 34 & 55 & 63 & 67 & 70 \\
\hline & & & 4 & 0 & 0 & 0 & 3 & 5 & 6 & 7 \\
\hline 4 & IB-N & 45 & 3 & 1 & 1 & 2 & 3 & 4 & 4 & 5 \\
\hline \multirow[t]{2}{*}{5} & VIIA-N & 78 & 3 & 54 & 66 & 75 & 76 & 78 & & \\
\hline & & & 4 & 4 & 6 & & 7 & 8 & & \\
\hline \multirow[t]{2}{*}{6} & VIIB-N & 78 & 3 & 60 & 71 & 77 & 79 & 81 & 82 & \\
\hline & & & 4 & 4 & 6 & 7 & 7 & 8 & 9 & \\
\hline \multirow[t]{2}{*}{7} & VIIIC-N & 78 & 3 & 58 & 69 & 76 & 78 & 80 & 80 & 79 \\
\hline & & & 4 & 3 & 7 & 6 & 8 & 7 & 8 & 7 \\
\hline \multirow[t]{2}{*}{8} & $\mathrm{TBAB}^{\mathrm{C}}$ & 60 & 3 & 77 & 81 & 83 & 83 & 83 & 83 & \\
\hline & & & 4 & 9 & 10 & 11 & 11 & 11 & 12 & \\
\hline
\end{tabular}

a 1, $2.01 \mathrm{mmol}$; 2a, $6.00 \mathrm{mmol} ; n-\mathrm{C}_{16} \mathrm{H}_{34}$ (as internal standard of GLPC), $1.30 \mathrm{mmol} ; 50 \% \mathrm{NaOH}, 2.8 \mathrm{~g}$; hexane, $2.0 \mathrm{~cm}^{3}$; quaternary ammonium group, $3 \mathrm{~mol} \%$ to 1 .

b Determined by GLPC.

c TBAB refers to tetrabutylammonium bromide.

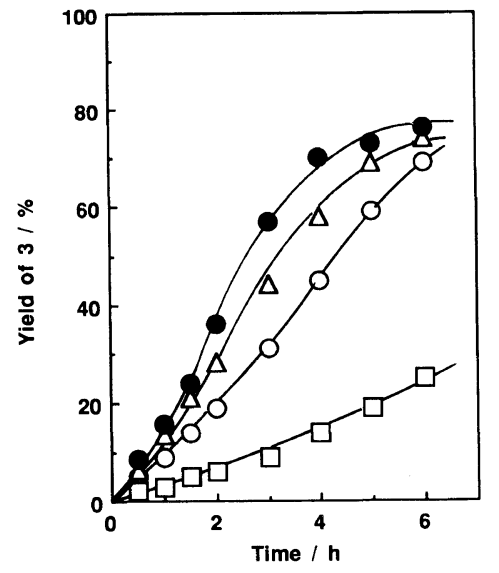

Figure 3. Time-yield curves for $\mathbf{3}$ in catalyses with polymeric PTCs at $65^{\circ} \mathrm{C}$. For PTC and its amount in mol\% to 1: (O) VIA-N, 3; $(\square)$ VIB-N, 3; $(\triangle)$ IIA-2N, 2;

IIA-1N, 2. For reaction conditions see Table VI.

Figure 4, a phase-transfer catalytic reaction in the presence of IIID-2N, which has a cross-linking level of $20 \mathrm{~mol} \% \mathrm{DVB}$ and grain size of $16-32 \mathrm{mesh}$, gave 3 after $4 \mathrm{~h}$ in a

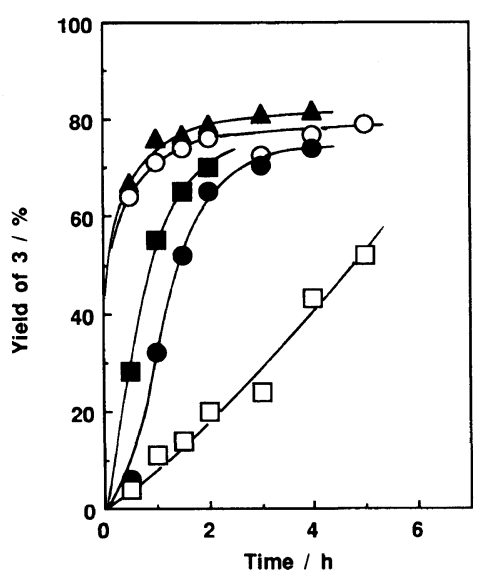

Figure 4. Time-yield curves for 3 in catalyses with polymeric PTCs $(3 \mathrm{~mol} \%$ to 1$)$ at $78^{\circ} \mathrm{C}$. For PTC and its grain size in mesh: $(\boldsymbol{\Delta})$ IIID-1N, 60-100; (○) IIID-2N, 16-32; (O) IIID-2N', 60-100; ( $\square)$ IX-N, 8-32; ( $\square$ ) IX-N', $60-100$. For reaction conditions see Table VI.

$74 \%$ yield, which is comparable to a final yield $77 \%$ in the catalysis using IIID- $2 \mathrm{~N}^{\prime}$ with the same cross-linking level but with the grain 
size of $60-100$ mesh. However, catalysis with IIID- $2 \mathrm{~N}$ gave $\mathbf{3}$ very slowly over an early reaction period and thereafter the formation of 3 at an accelerated speed was observed. The catalyst recovered from the above reaction mixture by filtration had a grain size below 60 mesh, indicating that particles of the initially used PTC were ground into those of smaller grain size by means of a magnetic stirrer bar used for agitating the heterogeneous reaction contents vigorously. When a PTC IX-N containing both $36 \mathrm{~mol} \%$ of 5 and $1 \mathrm{~mol} \%$ of DVB as cross-linking agents was used under the same reaction conditions, the yield of $\mathbf{3}$ increased slowly and recovered PTC had 8 - 32 mesh of grain size not different from that of the initially used PTC. The catalytic activity of IX-N', obtained by grinding IX-N into particles with $60-100$ mesh of grain size, was remarkably enhanced under reaction conditions comparable to the above. These results indicate that a considerable amount of a dormant quaternary ammonium salt which cannot exhibit its catalyzing ability lies inside the PTC and that 5-cross-linked polymeric supports are not broken into particles of smaller grain size during these phase-transfer catalysis. On the other hand, the polymeric support IIID-2 with $20 \mathrm{~mol} \%$ of DVB is brittle, as frequently observed for DVB-cross-linked polystyrene gels of macroporous type. Thus, the resin IIID-2 is also thought to be macroporous due to its preparation method (see EXPERIMENTAL). The swellability of the polystyrene-polyoxetane composite network in solvents of the present catalyses was influenced considerably by DVB units in only $1 \mathrm{~mol} \%$ in the network, while the network was swollen thoroughly with polar solvents such as DMF, used for the quaternization of the pendant bromide, in a manner similar to that of the polymeric support of DVB-cross-linked polystyrenes IIID-1 and IIID-2.

\section{Effect of Spacers of Polymeric PTCs}

The influence of spacer length of polymeric
PTC on catalytic activity was investigated by a comparison between phase-transfer catalysis using PTCs with a 1-oxapentamethylene or methylene spacer (Figure 3). Obviously, the long spacer of PTCs IIA- $1 \mathrm{~N}$ and IIA-2N favors catalysis compared with the short spacer of PTCs VIA-N and VIB-N, in spite of the similarity of mole fractions for monomeric units 5 and 12 in these four polymeric supports. However, the existence of the chloride counteranion in place of the bromide counteranion toward the pendant ammonium cation of PTCs VIA-N and VIB-N is not responsible for lowering their catalytic activities, since it is generally known that when chloride and bromide counteranions are exchanged for anionic species which act as nucleophiles, on the quaternary ammonium cation of a PTC, the chloride anion favors anion-exchange reaction more than the bromide anion. ${ }^{14}$ In the present phase-transfer catalysis, though the chloride anion tends to anion-exchange more smoothly for an anionic nucleophile on a quaternary ammonium countercation than the bromide anion, VIA-N and VIB-N having chloride counteranions showed lower catalytic activity than those of IIA-1N and IIA-2N having bromide counteranions, indicating spacer effect on catalytic activity.

When PTCs with the methylene spacer were used in the catalysis under the same reaction conditions, the catalytic activity of VIB-N prepared by Method B was considerably lower than that of the analogue prepared by Method $A$ ( $O$ and $\square$ in Figure 3), although the catalytic activities of PTCs with the long spacer of an 1-oxapentamethylene chain seemed almost comparable to each other regardless of the preparation methods of the polymeric supports (Table VI). An important role of spacers was also investigated on phase-transfer catalysis using several spacer-modified polymeric PTCs. ${ }^{4}$

Some investigations have been reported for phase-transfer catalytic reactions of chloromethylated polystyrenes. ${ }^{15-18}$ A poly(chloro- 
methylstyrenes) prepared from a 2:3 molar $m$ - and $p$-isomeric mixture of $\mathbf{6}$ was dissolved in toluene and used in phase-transfer catalysis with KOAc in the presence of TBAB. This catalysis gave D.F of 0.70 by 24 h-reaction at $30^{\circ} \mathrm{C} .{ }^{18}$ The somewhat low D.F of the product polymer is probably due to the short spacer of pendant benzylic chlorides, although they seem fairly reactive even at low reaction temperatures around $30^{\circ} \mathrm{C}$. When swollen in $o$ dichlorobenzene to be used in a phase-transfer catalysis with KOAc and TBAB, a chloromethylated 1\% DVB-cross-linked polystyrene with a D.F of 0.205 showed a conversion of 0.98 after a long reaction period of 4 days at $100^{\circ}$ C. ${ }^{15}$ Such conditions may be required due to the steric crowding of polystyrene matrices, in spite of being swollen by the polar solvent, rather than the short spacer of the chloromethyl group. The resultant acetoxyl groups of the polystyrene resin were completely hydrolyzed after 2 days under phase-transfer catalytic conditions using tetrabutylammonium hydroxide in $50 \mathrm{wt} \%$ aqueous $\mathrm{KOH}$ and $o$-dichlorobenzene at $85^{\circ} \mathrm{C}$. The esterification and hydrolysis reactions of the pendant terminal groups of composite resins such as IIA-2 were finished within shorter periods of $4-5 \mathrm{~h}$ using benzene or aqueous methanol as the solvent at $60-80^{\circ} \mathrm{C}$. Thus, only the swelling of polymer matrices but also the expanding of soft polyether networks by heat are important. In such expanded polymer matrices, the pendant substrates anchored at the end of an adequately long spacer attain greater reactivity than those of shorter-spacer-anchored substrates.

This study shows that several polymer reactions of the pendant groups at the spacerend of polyether-network-containing polystyrenes were possible with fairly good D.Fs.
The solftness and expanding ability of moderately polar polyether networks and existence of adequately long spacers in the networks may also be important for obtaining good D.Fs. Data on these polymer reactions should help clarify role of a new type of polystyrene resins different from DVB-crosslinked polystyrenes used widely.

\section{REFERENCES}

1. A. Akelah and D. C. Sherrington, Chem. Rev., 81, 557 (1981).

2. A. Akelak, Synthesis, 413 (1981).

3. M. Tomoi, E. Ogawa, Y. Hosokawa, and H. Kakiuchi, J. Polym. Sci., Polym. Chem. Ed., 20, 3015 (1982).

4. M. Tomoi, S. Shiiki, and H. Kakiuchi, Makromol. Chem., 187, 357 (1986).

5. M. Motoi, H. Suda, K. Shimamura, S. Nagahara, M. Takei, and S. Kanoh, Bull. Chem. Soc. Jpn., 61, 1653 (1988).

6. M. Motoi, S. Nagahara, M. Yokoyama, S. Kanoh, and H. Suda, Kobunshi Ronbunshu, 46, 69 (1989).

7. M. Motoi, K. Shimamura, C. Shimamura, S. Muramoto, S. Kanoh, and H. Suda, Bull. Chem. Soc. Jpn., 62, 2553 (1989).

8. M. Motoi, S. Nagahara, H. Akiyama, M. Horiuchi, and S. Kanoh, Polym. J., 21, 987 (1989).

9. E. G. Corey and N. Raju, Tetrahedron Lett., 24, 5571 (1983).

10. I. B. Rose, J. Chem. Soc., 542 (1956).

11. G. O. Gutekunst and H. L. Gray, J. Am. Chem. Soc., 44, 1741 (1922).

12. M. Motoi, H. Suda, M. Kijima, T. Doi, T. Nakagawa, and S. Kanoh, Polym. J., 21, 451 (1989).

13. D. F. DeTar and M. N. Turetzky, J. Am. Chem. Soc., 77, 1745 (1955).

14. E. V. Dehmlow and S. S. Dehmlow, "Phase Transfer Catalysis," Verlag, Weinheim, 1980, pp 13-17.

15. J. M. J. Fréchet, M. D. de Smet, and J. Farrall, J. Org. Chem., 44, 1774 (1979).

16. T. Nishikubo, T. Iizawa, K. Kobayashi, Y. Masuda, and M. Okawara, Macromolecules, 16, 722 (1983).

17. T. Nishikubo, T. Iizawa, S. Akatsuka, and M. Okawara, Polym. J., 15, 911 (1983).

18. T. Iizawa, T. Nishikubo, Y. Masuda, and M. Okawara, Macromolecules, 17, 992 (1984). 